\title{
Elements that compose the non-profit BRAND orientation in an emerging country
}

\author{
Lara Mendes Christ Bonella Sepulcri ${ }^{1}$ (D) Emerson Wagner Mainardes ${ }^{1}$ (D)
}

Received: 20 May 2021 / Accepted: 26 January 2022 / Published online: 5 February 2022

(c) The Author(s), under exclusive licence to Springer-Verlag GmbH Germany, part of Springer Nature 2022

\begin{abstract}
This study grouped and systematized the elements that make up non-profit brand orientation (NBO) in an emerging country, as well as the elements that precede nonprofit brand orientation, and the consequences of, and barriers to, the implementation of this strategy. The country studied was Brazil. We carried out an exploratory quantitative study based on the theoretical concept of brand orientation, with data collected from a questionnaire with statements generated in qualitative initial research. We collected 223 valid questionnaires and submitted them to exploratory factor analysis (EFA). We found that NBO in an emerging country is a higher-order reflective construct composed of two lower-order reflective constructs (communication and cause). The antecedents of NBO resulted in a set of reflective constructs of the first order (organizational factors, market factors, and action). We also found four first-order reflective constructs as a consequence of NBO (fundraising, partnerships, staff relationships, and social influence). The barriers to NBO constitute a higher-order reflective construct, composed of four lower-order reflective constructs (communication challenges, commercial aversion, barriers to donation, and economic context). We conclude that, in the presence of the antecedents of NBO in an emerging country, a non-profit organization tends to develop NBO and thus achieves several benefits. However, barriers to NBO hinder both the implementation of NBO and the achievement of the benefits resulting from this strategic orientation.
\end{abstract}

Keywords Non-profit brand orientation · Emergent country · Brazil · Antecedents · Consequents $\cdot$ Barriers

Emerson Wagner Mainardes

emerson@fucape.br; emerson.mainardes@pq.cnpq.br

Lara Mendes Christ Bonella Sepulcri

lara.sepulcri@aluno.fucape.br

1 FUCAPE Business School, Av. Fernando Ferrari, 1358, Boa Vista, Vitória/ES 29075-505, Brazil 


\section{Introduction}

The growth of the third sector around the world has increased competition for financial resources and volunteers (Apaydin, 2011; Casey, 2016; Randle et al., 2013). The global crisis resulting from COVID-19 has emphasized the importance of the performance of the third sector, particularly in serving the most vulnerable populations. The crisis helped drive increased donations to the third sector. In Brazil, which faces structural problems, donations from the private sector raised more than BRL 6 billion for this cause to July 2020 (Brazilian Association of Fund Raisers, 2020). The lack of a culture of giving, economic crises, and distrust of civil society organizations, here termed non-profit organizations (NPOs), has led these organizations to seek alternatives to face the challenges. Associations with the private sector, with governments, and/or with other third sector organizations, attracting volunteers and adopting marketing strategies, have proved to be efficient ways to face these barriers (Institute for the Development of Social Investment [IDIS], 2020; Richelieu \& Korai, 2012; Sheth, 2011).

In this context, NPOs can give donors the confidence to make more donations, improve communication about the social results achieved and foster partnerships with other institutions by implementing a non-profit brand orientation strategy - NBO (da Silva et al., 2020a; Garg et al., 2019; IDIS, 2020; Laidler Kylander \& Simonin, 2009; Venable et al., 2005). This strategy involves the brand as the center of the organization and can be understood as the degree to which nonprofit organizations consider themselves a brand (Hankinson, 2000; Urde, 1994, 1999). On the basis of previous qualitative analysis (Sepulcri, Mainardes, \& Pascuci, 2020), our study grouped and systematized the elements that make up non-profit brand orientation in an emerging country, defining the constructs that reflect this strategy, as well as the elements that precede non-profit brand orientation, and the consequences and barriers to the implementation of this strategy. In this case, the country studied was Brazil.

Our study is theoretically justified in that it seeks to understand empirically how the peculiarities of developing economies affect non-profit brand orientation, and its causes and benefits, as well as the challenges to the implementation of this strategy. This is rare, as most studies of this nature are concentrated in developed countries (Anees-Ur-Rehman et al., 2016; Sepulcri, Mainardes, \& Marchiori, 2020). The third sector is even more necessary in developing economies due to their social deficiencies. For example, in Brazil, in 2018, there were more than seven hundred and eighty thousand formally registered civil society organizations (Lopez, 2018). Understanding NBO can help managers of NPOs to better apply a brand-central strategy, with greater social impact, and favoring success in fulfilling their missions.

Our research expands the investigation of concepts that can be added to previous research (Apaydın, 2011; Evans et al., 2012; Ewing \& Napoli, 2005; Hankinson, 2001) and can be applied in distinct non-profit sectors. This is because, whereas our study intends to be more general, previous studies that set out to understand or measure non-profit brand orientation, considering its background 
and barriers, kept the focus on a specific sector, such as museums (Evans et al., 2012), or lack empirical tests for the proposed relationships (for example, Apaydin, 2011).

\section{Literature review}

\subsection{The third sector in emerging economies}

Emerging markets still suffer from economic and social issues, such as a high level of corruption, instability in legislation, lack of qualified labor, and insufficient basic social services (Casey, 2016; Ernst et al., 2015; Kuti, 1999; Richelieu \& Korai, 2012). Understanding the particularities of these markets is important for the success of the organizations that operate in them, and for the adaptation of marketing strategies that differ from those in developed markets, whether for cultural, social or economic reasons (Bevilacqua et al., 2020; Casey, 2016; Moraes \& Strehlau, 2020; Paul, 2020; Sheth, 2011). The political and economic aspects of emerging countries also impact the relationship between the non-profit and the public sector. Some of these countries, including Brazil, just recently experienced a transition to democracy, although this transition has not been fully consolidated in some of them (Casey, 2016, 2020). Non-profit organizations are based on independent civil society organization; thus, it is required to its development the legitimacy of the state and a certain degree of freedom to not be considered as a clandestine opposition network (Casey, 2020; Toepler et al., 2020).

NPOs in emerging markets have reached areas that were previously inaccessible and fulfilled their mission through innovative solutions (Shankar \& Narang, 2019; Sheth, 2011). For example, according to the Best NGOs Guide 2018 (Doar Institute, 2018), of the NPOs which won the 100 best non-governmental organizations award in 2018 (an award recognizing the 100 best Brazilian NPOs based on third sector excellence practices), 27 NPOs were linked to social assistance; that is, they worked with vulnerable communities. One of these was Artemisia, which promotes social businesses, supporting "businesses aimed at the population in a situation of economic vulnerability, which create solutions for socio-environmental problems" (Artemisia, 2020). Such solutions are created in environments with limited resources and need to solve specific problems at a low cost (Shankar \& Narang, 2019).

In Brazil, a non-profit organization is defined as a private non-profit organization, legally constituted from a voluntary initiative and self-managed (Institute of Applied Economic Research [IPEA], 2021). It means that any free person can start an NPO. Also, the Brazilian NPOs are categorized in social assistance; employers, professionals, and rural producer associations; culture and recreation; defence of rights and interests; education and research; housing; environment and animal protection; health; religion; and others. In 2020, most of them were categorized as defence of rights and interests (45.5\%), religion (20.4\%) and culture and recreation (11.9\%), according to IPEA (2021).

Despite the importance of NPO in so many different areas, these organizations suffer from lack of trust, especially after corruption episodes involving Brazilian government 
and some NPOs (see Hopstein \& Peres, 2021). However, many efforts in terms of regulation have been made to enhance transparency and accountability in the third sector, especially in Brazil, and online and local funds started to grow to support these organizations and their initiatives (Hopstein \& Peres, 2021).

The financing of these third sector organizations is usually through donations, independent volunteers, and partnerships with public and private for-profit organizations (Casey, 2016), and so, in order to achieve their objectives, NPOs must use marketing strategies to improve fundraising in regard to human and financial resources (da Silva et al., 2020a; Ernst et al., 2015; Richelieu \& Korai, 2012; Sheth, 2011). These strategies can be seen, for example, in the context of donors. Mainardes et al. (2017) found that the brand of a non-profit organization tends to influence Brazilian donors of goods and money to make their donations.

A brand's influence is related to variables such as the understanding of the brand, past credibility, and transparency (Mainardes et al., 2017). Such variables were tested by Garg et al. (2019), who developed a model to measure brand effectiveness, based on a sample from India, which is also considered an emerging country. According to the findings, the brand of non-profit organizations in India proved to be an important tool, both for fundraising and for fulfilling the NPO's mission (Garg et al., 2019).

Reinforcing the importance of the brands to NPOs in emerging countries, Maleki and Hosseini (2020) found that consumer-brand engagement is a predictor of intention to donate via m-payment apps in Iran. This shows the importance of brands in online environments as well, which justifies the NPO brand research in emerging countries.

\subsection{Brand and brand orientation}

As a strategic attribute, a brand goes beyond graphic symbols; it represents an organization's promise and how it generates value for its audience (Tilley, 1999; Urde, 1999). Thus, brand orientation is based on creating, developing, and protecting the organization's brand (Urde, 1994, 1999). In this strategy, the brand is seen as the center of the organization and as a driver of decision-making by the organization (Urde, 1994, 1999).

However, although a brand is considered strategic, it is still not always considered at all levels of organizations' marketing strategies (Cant et al., 2013). The application of a brand orientation strategy has been shown to positively affect organizational aspects such as brand performance (Chang et al., 2018; Laukkanen et al., 2013; Wong \& Merrilees, 2015), brand value (Baumgarth \& Schmidt, 2010; Zhang et al., 2016), employee commitment (King \& So, 2015; Liu et al., 2015), consumer engagement (Wirtz et al., 2013), and organizational performance (Liu et al., 2015; Wong \& Merrilees, 2015).

\subsection{Brand orientation in the third sector}

From the perspective of non-profit organizations, the brand also represents the cause defended by that organization (Hankinson, 2000). A non-profit brand orientation strategy is linked to a brand's understanding and communication, the use of the brand as a strategic resource, and the deliberate and active management of that 
resource (Hankinson, 2001). As NBO focuses on developing the brands of these organizations (Hankinson, 2001), it can have influence, for example, in partnerships with for-profit organizations looking for NPO brands that share their values to develop a cause-related marketing strategy (da Silva et al., 2020b).

Ewing and Napoli (2005) proposed a model to measure NBO based on interaction, which is linked to an organization's dialogue with stakeholders and the ability to adapt to the environment; orchestration, which is linked to communication alignment both internally and externally; and affection, related to understanding stakeholder satisfaction with the organization. By qualitatively analyzing the elements that form brand orientation in Brazil, Sepulcri, Mainardes, and Pascuci (2020) perceived variables related to communication, management, and brand understanding, and added variables to these elements such as communication of the social results achieved, responding to market changes, and brand-focused training for NPO employees and volunteers. Sepulcri, Mainardes, and Pascuci (2020) also suggested variables related to brand creation (Urde, 1999), such as logo, name, and other symbols, which should reflect the mission, the cause, and the values of an NPO, thus making up the non-profit brand orientation, according to the same authors. In summary, the authors found 28 variables that compose the NBO. This set of variables were evaluated by four scholars, reducing to a final set of 24 variables, which can be seen in the appendix Table 6.

\subsection{Antecedents, consequents and barriers to brand orientation in the third sector}

The antecedents of brand orientation can be attributed to factors internal to a nonprofit organization, such as the personal views of managers, their experience with brand management, leadership, resources to implement the brand strategy and organizational culture (Apaydın, 2011; Evans et al., 2012; Hankinson, 2001). There are also external factors, such as direct and indirect competition, types of financing, and environmental factors (Apaydın, 2011; Evans et al., 2012; Hankinson, 2001), which mean NPOs need to differentiate themselves from others through their brand to increase resources (Laidler Kylander \& Simonin, 2009; Napoli, 2006). Sepulcri, Mainardes, and Pascuci (2020) also discuss the degree of NPO involvement in communities, which acts as a factor leading NPOs to prioritize the brand and support the implementation of strategies such as NBO, to achieve its benefits. Seventeen variables classified as antecedents to NBO were found by Sepulcri, Mainardes, and Pascuci (2020). These variables were evaluated by four scholars, reducing the antecedents used in this study to 14 (Appendix Table 6).

As in the for-profit sector, NPOs can also benefit from working consistently with their brands; better connections with their target audiences; improving reputation, political impact and trust levels among stakeholders; and differentiating themselves from other non-profit organizations (Boenigk \& Becker, 2016; Curran et al., 2016; Durgee, 2016; Khan \& Ede, 2009; Laidler Kylander \& Simonin, 2009; Michel \& Rieunier, 2012; Voeth \& Herbst, 2008; Wong \& Merrilees, 2005). Ultimately, brand orientation also improves an organization's performance in the non-profit sector 
(Liu et al., 2015; Napoli, 2006). Implementing NBO makes it possible not only to bring more financial and human resources to an NPO, either through partnerships with for-profit companies or by attracting more individuals who will donate their time and money, but to improve the alignment between internal employees and NPO objectives (King et al., 2013; Liu et al., 2015, 2017; Sepulcri, Mainardes, \& Pascuci, 2020). Twenty-eight variables classified were found as consequents of NBO by Sepulcri, Mainardes, and Pascuci (2020). The variables were then analyzed by four scholars and reduced to the 27 consequents used in this study (see appendix Table 6).

Finally, barriers to the implementation of NBO include a lack of understanding of marketing concepts and tools by employees; negative associations with brand terminology; human, financial, and time limitations; and size and organizational structure (Chad et al., 2013; Evans et al., 2012; Lee \& Markham, 2015; Stride \& Lee, 2007; Wong \& Merrilees, 2005). Sepulcri, Mainardes, and Pascuci (2020) also showed that there is a feeling of aversion among NPOs to practices that are considered very commercial, such as some branding strategies, and that this aversion is reinforced by donors of time, money, or goods. This confirms Stride and Lee's (2007) findings, which indicate an aversion to the term "brand" even by nonprofit managers. So, is interesting to note that brand, in the nonprofit sector, is often associated with commercial practices, as if the organization had the main purpose of selling, which implies profit, instead of social change (Andreasen, 2012; Sepulcri, Mainardes, \& Pascuci, 2020; Stride \& Lee, 2007).

Government plays a dual role in the context of an emerging market, as an organization financier and as a barrier to NBO, given that brand makes no difference to competition for public resources, discouraging NPOs that have the government as the main sponsor, from investing in their brand (Sepulcri, Mainardes, \& Pascuci, 2020). Sepulcri, Mainardes, and Pascuci (2020) found 29 variables that were classified as barriers to NBO. The scholars' evaluation reduced this to 26 variables, which are used in this study (see appendix Table 6).

In summary, the questionnaire used in this study is based on the elements that compose the NBO, its antecedents, consequents, and the barriers to NBO, found by Sepulcri, Mainardes, and Pascuci (2020), reported in the appendix Table 6 and totaling 91 variables. The intention here was to develop a way to measure the brand orientation of non-profit organizations in an emerging country, observing elements that are relevant to guiding the brands of these organizations and that can contribute to strengthening the third sector.

\section{Methods}

We conducted exploratory quantitative cross-sectional research in order to fulfill the objective of this study, which is to group and systematize the elements that compose the non-profit brand orientation in an emerging country, as well as the elements that precede non-profit brand orientation, and the consequents and barriers to the implementation of this strategy. The study is characterized as exploratory quantitative, since it uses quantitative data to explore a phenomenon (non-profit brand 
orientation) in a little-known context (emerging markets), in order to identify the factors that explain this phenomenon. It is also characterized as a cross-sectional study since the investigation was carried out during a specific period in time. The field of study was composed of non-profit organizations, since the decision to implement a non-profit brand orientation strategy is made by the NPO and it is also implemented in the organization.

The target population was NPO employees, volunteers (donors of time), donors of money or goods, and non-donors, in order to consider the different realities of the various stakeholders who influence a non-profit brand orientation strategy, as well as its barriers, antecedents, and consequents. Given the difficulty of measuring and accessing the entire target population, we opted for non-probability sampling for accessibility; that is, we sought to reach the maximum number of subjects that were part of the target population and were available to participate in the study.

We developed a questionnaire for data collection with statements that were predefined by the researchers from the elements resulting from previous qualitative research (Sepulcri, Mainardes, \& Pascuci, 2020). The statements in the initial questionnaire were evaluated by four scholars, including three researchers working in the marketing sector in the third sector and one specialist in scales (Boateng et al., 2018). Changes were proposed on the basis of these evaluations, regarding the writing and the number of statements, thus explaining the difference between the number of statements in the initial questionnaire (102 statements) and the final questionnaire (91 statements - Appendix Table 6).

Once the statement content was validated by the specialists, and the suggested changes were accepted, the questionnaire was elaborated in six parts. The first part introduced the research and the target audience and included two control questions: the first asking which group the respondent belonged to, and then, if applicable, their position in the non-profit organization. Four blocks of questions were then presented, comprising: 24 statements about NBO (O1 to O24), 14 statements about the NBO's antecedents (A1 to A14), 27 statements about the consequents of NBO (C1 to $\mathrm{C} 27$ ) and 26 statements about barriers to NBO (B1 to B26). We used a 5-point Likert scale to measure degrees of agreement with the statements. The last block was composed of 12 questions that characterized the respondents in regard to age, gender, income, region where they live, occupation, marital status, education, number of non-profit organizations they know, proximity to the non-profit organizations they attend, degree of importance of non-profit organizations, and length of employment. The final questionnaire contained 105 questions.

The questionnaire was sent in electronic format for a pre-test with 12 respondents, three respondents from each group of the target population (employees of nonprofit organizations, volunteers, donors of goods and/or money, and non-donors) which resulted in modifications to the questionnaire until there were no more doubts (Boateng et al., 2018). Only after this procedure was the questionnaire released online using a google forms link on social networks, WhatsApp, and by e-mail. The social media channel and WhatsApp were used to collect data from donors and nondonors. We also carried out data collection in the field with in-person visits to the NPOs, where some questionnaires were filled out in print and others in an online format. Due the difficulty of reaching volunteers and NPO employees, we chose to 
visit the NPO in person in order to obtain more respondents from these groups of the target population. Data collection took place between October and December 2020. In all, 225 questionnaires were answered. Two questionnaires were discarded because they were not completely answered, so that the total sample of this study was 223 valid questionnaires.

We used Inter-item (II) and Item-total (IT) correlations for data analysis, to examine the relationship between the individual items (Boateng et al., 2018), followed by exploratory factor analysis (EFA), which aims to systematize and group the proposed elements into factors (Hair Jr. et al., 2009). Both were performed in SPSS 27. Inter-item correlations mean it is possible to evaluate the relationship of one item with each of the other items in the pool, and Item-total correlations evaluate the relationship of one item with the total score of the pool (Boateng et al., 2018). EFA means it is possible to verify the extent and consistency of the relationships between the observed variables, which are grouped into factors, without a priori defining the number of factors generated by the estimation (Boateng et al., 2018; Hair Jr. et al., 2009). Each factor generated from the EFA techniques therefore represents a latent variable, formed by a set of variables observed and highly correlated with each other (Boateng et al., 2018; Hair Jr. et al., 2009).

\section{Findings}

\subsection{Sample characterization}

Most of the respondents considered themselves mainly as employees of a non-profit organization $(32.7 \%)$, followed respectively by non-donors $(26.9 \%)$, volunteers (17.9\%), donors of money or goods (13.9\%), and a small portion of respondents who considered themselves as having other connection (8.5\%). When the employees or volunteers were linked to an NPO $6.3 \%$ of the respondents acted as directors, $4.9 \%$ acted as managers, $14.8 \%$ worked in the operational or technical area and $23.3 \%$ said they worked in another role.

It should be noted that many non-profit organizations, especially smaller ones, do not have well-defined roles within their staff and volunteers. A complete description of the respondents is summarized in Table 1.

Most of the respondents consider non-profit organizations to be very or extremely important $(79.37 \%)$, and more than half of them had engaged with these organizations for five years or more (50.22\%). Considering NPOs' employees, the respondents participated in the activities of non-profit organizations or made donations mostly monthly or weekly $(56.95 \%)$, however, a portion participate only sporadically $(19.73 \%)$.

The organizations supported are, in general, close to home, work or in the same municipality as the respondent resides (64.13\%). Support for foreign NPOs is low $(0.45 \%)$. Most respondents also showed that they knew more than two non-profit organizations (77.58\%), although $35.4 \%$ were not donors or employees of an NPO. The data presented is in accordance with the report of the Charities Aid Foundation 
(CAF), which points out that most Brazilians have a positive outlook on NPOs and that they tend to donate to local causes (IDIS, 2020).

As for the sociodemographic characteristics, $58.74 \%$ of the respondents were women, who, according to $\mathrm{CAF}$, are more likely than men to make donations or engage with social causes in various situations (IDIS, 2020). It is worth mentioning that in 2018 women accounted for $65 \%$ of the NPO workforce (Lopez, 2018). $80.27 \%$ of the sample was aged between 21 and 50 years old, married (55.16\%), and had an elevated level of education, as $82.96 \%$ declared having higher or postgraduate education.

Respondents were located predominantly in the southeast region of Brazil (83.86\%), where most of the Brazilian population is located, and where $40 \%$ of formally constituted NPOs were located in 2018 (Lopez, 2018), that is, the most NPOs in Brazil.

The respondents were mostly active in the for-profit private sector $(40.81 \%)$, and $36.32 \%$ had a monthly income between 2001 and 5000 BRL, comparable with the average income in Brazil (Brazilian Institute of Statistical Geography, 2020). In short, the characterization of the sample meets the requirements of the target population and demonstrates the reality of Brazilian non-profit organizations, meaning that it is adequate for this study.

\subsection{Non-profit brand orientation construct}

When examining Inter-item (II) and Item-total (IT) correlations, very low correlations $(<0.3)$ indicate possible items for deletion from the pool. In this case, only O1 showed low correlation in both estimations (II correlations between 0.037 and 0.411 , and IT correlation equal to 0.271 ), and was characterized as a possible item for exclusion (Boateng et al., 2018). The other items presented II between 0.135 and 0.759 and IT from 0.357 to 0.770 . We performed a type R EFA, given the objective of grouping the variables and identifying the constructs that constitute the proposed model, determining the latent dimensions (Hair Jr. et al., 2009).

We used Bartlett's sphericity test to verify the adequacy of the sample to the factor analysis procedures, in which $\mathrm{p}<0.05$ values are accepted, the Kaiser-MeyerOlkin (KMO) test and the anti-image correlation matrix, from which we analyzed whether the values of the main diagonal met the measure of sampling adequacy (MSA). Values above 0.5 were accepted as adequate for KMO and the main diagonal values of the anti-image correlation (Hair Jr. et al., 2009). The correlation matrix was verified, and there was no evidence of multicollinearity (Boateng et al., 2018). We used principal component analysis for the extraction of the factors, with an eigenvalue greater than 1, and Varimax orthogonal rotation, given its suitability for data reduction (Hair Jr. et al., 2009). As suggested by Boateng et al. (2018), the factors were also rotated using oblique rotation, however the results did not show significant differences. Thus, we opted for the Varimax rotation, which is more commonly used (Hair Jr. et al., 2009).

For the decision to maintain the variables and constructs, the explained variance was verified. It was considered adequate when greater than or equal to $60 \%$, 
the communalities, were considered adequate with values greater than 0.5 , and the factor loadings were considered adequate when greater than 0.4 in the absence of crossed loadings. We considered the variables that had loadings in more than one construct with a difference of less than 0.1 between them, as cross-loadings (Hair Jr. et al., 2009). We used the Cronbach's alpha value to assess the reliability of the constructs. Although values above 0.70 are considered ideal for Cronbach's alpha (Hair Jr. et al., 2009), values above 0.60 are admitted in exploratory studies (Hair Jr. et al., 2009) and were considered acceptable in the present study.

The first EFA aimed to identify the constructs that represent non-profit brand orientation in an emerging country. We started with 24 initial variables (O1 to O24), and excluded 9 variables: O1, O2, O3, and $\mathrm{O} 4$ for not fitting into the 2 constructs extracted; O9, O12, and $\mathrm{O} 22$ due to low commonality; and $\mathrm{O} 7$ and O13 due to cross-loading problems. After excluding the variables, the results presented a model with a KMO of 0.917 , and significance $<0.05$ in Bartlett's sphericity test. Two constructs were extracted: F1, termed "communication" (=COM) and composed of the variables $\mathrm{O} 24, \mathrm{O} 23, \mathrm{O} 17, \mathrm{O} 21, \mathrm{O} 18, \mathrm{O} 19, \mathrm{O} 20, \mathrm{O} 15$, and O14; and F2, termed "cause" (=CAU) and composed of the variables O10, O8, O11, O6, O5. It should be noted that although O5 has a commonality below 0.5 , we chose to keep the variable given the proximity to the ideal value and adequate factor loading. The commonalities varied from 0.497 (variable O5) to 0.778 . The anti-image correlation matrix values of the main diagonal ranged from 0.866 to 0.961 . Table 2 provides a summary of the results of this analysis, as well as the factor loadings, the explained variance, and Cronbach's alpha of the constructs.

The allocation of F1 as communication was based on the understanding that the variables linked to this construct are related to the communication and relationship strategies of the NPO with different stakeholders. These strategies involve communicating the results $(\mathrm{O} 24)$, financial transparency $(\mathrm{O} 23)$, consistent brand promotion internally (O21 and O18) and externally (O19 and O16), alignment of NPO marketing practices (O15), closer relationship with audiences $(\mathrm{O} 20)$, and feedback evaluation (O17 and O14). F1 thus reflects the degree of communication established between the NPO brand and the various stakeholders. Communication was also considered one of the elements of the non-profit brand orientation proposed in the qualitative analysis carried out by Sepulcri, Mainardes, and Pascuci (2020). The key role of communication in building and developing brands is reinforced by empirical models, such as those by Ewing and Napoli (2005), and theoretical models, such as by Hankinson (2001).

The allocation of F2 as cause was due to the relationship between the NPO's brand and the reason for the existence of the non-profit organization, that is, the cause being defended (Sepulcri, Mainardes, \& Pascuci, 2020). It can be observed that the construct accesses the creation of symbols that represent the NPO's brand according to the cause, mission, and values of the non-profit organization (O10, O8, O11), generating affinity with its audiences (O6) and providing solidarity with people (O5). Hankinson (2000) reported in a qualitative analysis that the cause and values of an NPO are among the main aspects of the non-profit brand, which corroborates with the findings by Sepulcri, Mainardes, and Pascuci (2020). 
In summary, the NBO construct in an emerging country proved to be a reflective higher-order construct, which means that, as an NPO decides to be more brand-oriented, they need to improve the practices suggested in the variables, in line with the literature on the subject (Apaydın, 2011; Ewing \& Napoli, 2005; Hankinson, 2001; Mulyanegara, 2011). The NBO construct is thus composed of two reflective lowerorder constructs, termed cause and communication. Communication is a construct composed of ten variables $(\mathrm{O} 14, \mathrm{O} 15, \mathrm{O} 16 \mathrm{O} 17, \mathrm{O} 18, \mathrm{O} 19, \mathrm{O} 20, \mathrm{O} 21, \mathrm{O} 23$ and $\mathrm{O} 24)$, and cause is composed of five variables (O5, O6, O8, O10 and O11).

\subsection{Antecedents of non-profit brand orientation}

To identify the constructs that represent the antecedents to brand orientation in an emerging country, we carry out the II and IT correlations, followed by the EFA along the same lines as in item 4.2. Based on 14 initial variables (A1 and A14), although II correlations varied from 0.126 to 0.582 , the IT correlations did not show possible items to delete, as Item-total correlations were above the threshold of 0.3 for all items, from 0.400 to 0.686 . After running the EFA, variable A3 was excluded due to a low communality problem and A9 due to a cross-loading problem.

After exclusion, the result presented a model with a KMO of 0.883, and significance $<0.05$ in Bartlett's sphericity test. We extracted three constructs: F1, called "organizational factors" (=ORG) and composed of the variables A5, A4, A13, A10, A14, A6; F2, termed "market factors" (=MKT) and composed of the variables A7, A11, and A12; and F3, termed "action" (=ACT) and composed of the variables A2, A8, and A1. After excluding the variables, the commonalities varied from 0.520 to 0.733 . The anti-image correlation matrix values of the main diagonal ranged from 0.817 to 0.924 . A summary of the results of this analysis, as well as the factor loadings, the explained variance, and Cronbach's alpha of the constructs, can be seen in Table 3.

F1 was called organizational factors due to the perception that the variables related to the construct are linked to internal issues of non-profit organization and are evidenced by a clear understanding of the organization's performance (A5), for the existence of good management (A4, A14), by organizational culture (A13), for the quality of products and services offered (A10), and by the qualification of employees (A6). The variables that comprise the construct called organizational factors are aligned with the antecedents reported by authors such as Hankinson (2001) and Evans et al. (2012).

Similarly, F2 was called market factors, from the perception that the variables related to the construct are linked to the market in which NPO operates. In regard to competition (A7), this aspect was also demonstrated by Evans et al. (2012) as an antecedent to NBO. The need to attract volunteers and employees (A11) and the search for partnerships with for-profit companies (A12) were discussed by Hankinson (2000) in his qualitative study as areas that can benefit from the application of brand strategies. It is also worth noting that the idea of using a brand to differentiate oneself from competitors and then to obtain a competitive advantage is widely 
accepted for the adoption of strategies such as NBO (Casidy, 2013; Ewing \& Napoli, 2005; Mulyanegara, 2011; Urde, 1994).

Finally, F3 was named action, and is related to the development of an NPO in the region where it operates, based on the understanding of the social problem that the NPO is dedicated to solving or mitigating (A1) and demonstrating positive social impacts (A8), to then become a traditional organization where it operates (A2). It is argued that understanding the brand (Hankinson, 2001) comes from the knowledge of the cause by the NPO and the social problem that it proposes to mitigate or solve. The time factor, that is, the age of the NPO, seems to help to develop and propagate the brand of the non-profit organization (Sepulcri, Mainardes, \& Pascuci, 2020), when associated with a demonstration of the positive effects of the performance of the NPO in the community.

In short, antecedents cannot be considered a single higher-order construct, given the breadth and diversity of the concept of antecedents, that is, what leads an NPO to implement the brand orientation strategy. Antecedents were therefore considered a set of reflective lower-order constructs that represent antecedents to the implementation of the NBO strategy, as also proposed by Hankinson (2001).

\subsection{Consequents of non-profit brand orientation}

We conducted the II and IT correlations to identify the factors that represent the consequents of brand orientation in an emerging country, followed by the EFA again in the same manner as in Item 4.2. In this case, in 27 initial variables ( $\mathrm{C} 1$ to $\mathrm{C} 27$ ), the results of II varied from 0.055 to 0.671 , but IT varied from 0.376 to 0.717 and did not show possible items to delete, as all Item-total correlations were above the threshold of 0.3 . So, from the first EFA results, variable $\mathrm{C} 15$ was excluded due to the problem of commonality and cross-loadings, variables $\mathrm{C} 1, \mathrm{C} 6, \mathrm{C} 10, \mathrm{C} 20$ and C21 were excluded due to low commonality, and variables C3, C16, C8 and C9 were excluded due to the problem of cross-loadings.

After exclusion, the results presented a model with a KMO of 0.902, and significance $<0.05$ in Bartlett's sphericity test. We extracted four factors: F1, called "fundraising" (=FUN) and composed of the variables C12, C17, C14, C13, C18, and C7; F2, called "partnerships" (=PAR), and composed of the variables C24, C22, C23, C25, and C19; F3, called "staff relationships" (=STA), and composed of the variables C5, C3, C2, and C4; and F4, called "social influence" (=SOL), and composed of the variables $\mathrm{C} 27, \mathrm{C} 11$, and $\mathrm{C} 26$. After this, the commonalities varied between 0.585 and 0.765 . The anti-image correlation matrix values of the main diagonal ranged from 0.585 to 0.745 . The results of this analysis, as well as the factor loadings, the explained variance, and Cronbach's alpha of the factors can be seen in Table 4.

In the constructs that represent the consequents of NBO, F1 was named fundraising according to the perceived relationship between the variables that deal with fundraising from different sources $(\mathrm{C} 12)$ and that go beyond direct donation $(\mathrm{C} 18)$, donations of goods and/or money (C17), mobilizing people, that is, donating time (C13), and that are related to the brand image $(\mathrm{C} 7)$ and its good reputation $(\mathrm{C} 14)$. We therefore verified 
that one of the consequents of NBO is the facilitation of the acquisition of resources (financial or not), in line with authors such as Apaydin (2011), Napoli (2006) and Michel and Rieunier (2012). In fact, NBO was understood as a predictor of the intention to donate in Brazil (da Silva et al., 2020a).

In F2, named partnerships, the variables relate to facilitation in the realization of partnerships and association of brands (C22 and C23), either with other NPO (C24) or with private for-profit companies (C25). The relationship between the development of the brand in the non-profit sector and the effect on partners is also a consequent that has already been discussed in the literature (Laidler Kylander \& Simonin, 2009). The relationship between making partners and social awareness, explored by the C19 variable, can also be perceived here. The positive impact of partnerships in raising awareness about the cause was pointed out by Cooke (2010), in a qualitative study, as one of the benefits of the partnership between for-profit and non-profit companies.

$\mathrm{F} 3$, staff relationships, encompasses variables related to the effect of NBO on NPO staff, leading them to share the sense of purpose/mission (C5), increasing engagement (C3), aligning beliefs and values with the NPO (C2) and identifying with the cause (C4). Hankinson (2001) proposed NBO's positive effect on employee engagement, and it was then empirically tested by Liu et al. (2015), who concluded that brand orientation affects the development of an emotional bond with the brand and the delivery of services consistent with the NPO brand.

As the last construct that groups consequents to NBO, F4, which is social influence, gathers variables related to the organization's influence in the social sphere. It is thus argued that NPOs that have a better developed brand are more oriented to the brand and attract more interest from academics, which would facilitate partnership with the academia (C27). It is also possible that these organizations have a greater capacity to develop research into the cause advocated for (see, for example Projeto Tamar and Instituto Trata Brasil), and influence public policies (C26) regarding the cause they advocate for, generating gains for the cause (Apaydın, 2011; Candler \& Dumont, 2010). Finally, because they perceive the effects generated by the performance of the NPO, volunteers are more likely to remain there (Curran et al., 2016), as demonstrated by $\mathrm{C} 11$. By developing its brand, an NPO is able to increase its influence in society and consequently better fulfill its social mission, whether through association with academia, influencing public policies, or retaining volunteers, which often form the majority of the NPO workforce.

Like the antecedents, the consequents for NBO in an emerging country therefore do not represent a higher-order construct, but several reflective lower-order constructs. It is understood that the concept of consequents is broad; that is, the set of aspects that are affected by the implementation of NBO. The consequents of NBO were considered as a set of reflective lower-order constructs, as in Hankinson (2001), and Wong and Merrilees (2005).

\subsection{Barriers to non-profit brand orientation}

Finally, to identify the factors that are barriers to non-profit brand orientation in an emerging country, the II and IT correlations, followed by EFA, were carried out 
along the same lines as in Item 4.2. In 26 initial variables (B1 to B26), the results of II varied from 0.058 to 0.621 , and of IT varied from 0.437 to 0.650 , which did not indicate possible items to delete, as all Item-total correlations were above the threshold of 0.3. However, the first EFA results suggested the exclusion of variables B5, B24, and B25 due to low commonality; B3 for not fitting into any of the constructs extracted, and B13, B16, B19, and B22 for presenting cross-loadings.

After the exclusions, the result presented a model with a KMO of 0.846 , and significance $<0.05$ in Bartlett's sphericity test. Four constructs were extracted: F1, "communication challenges" (=COC), and composed of the variables B8, B6, B7, B10, and B9; F2, "commercial aversion" (=CAV), and composed of the variables B21, B14, B17, B18, and B23; F3, "barriers to donation" (=BDO), and composed of the variables B1, B4, B12, and B11; and F4, "Economic context" (=ECO), and composed of the variables B15, B26 and B20. Finally, the commonalities resulted in values from 0.501 to 0.694 and the main diagonal of the anti-image correlation matrix resulted in values from 0.751 to 0.885 . The result of this analysis, as well as the factor loadings, the explained variance, and the Cronbach's alpha of the constructs can be seen in Table 5 .

Of the four constructs that compose the barriers to NBO, F1, communication challenges, has variables identified as difficulties for the NPO to be able to communicate clearly and consistently with their stakeholders (Sepulcri, Mainardes, \& Pascuci, 2020). These difficulties include the size of the NPO (B8) and the difficulty in showing work that goes beyond the main cause (B9). According to reports by Sepulcri, Mainardes, and Pascuci (2020), these barriers seem to be greater the larger the size of the NPO and the more activities it undertakes in addition to the main cause. There also seems to be a lesser tendency to donate when there is a perception that the NPO already receives enough help, given that it is known to the general public (B6). On the other hand, donations, in some cases, are motivated by the perception of the general public that the organization needs help (Mainardes et al., 2017). This can lead some NPOs to focus more on showing the need for help than in developing communication that promotes their brands (B10). Despite the widespread use of social media, some NPOs still resist the widespread use of this resource for fear of criticism (Sepulcri, Mainardes, \& Pascuci, 2020), which is represented by variable B7.

The F2 construct, commercial aversion, gathers variables related to the NPO's aversion to using practices that seem very commercial (B18), an idea already discussed in the literature (Chad et al., 2013; Lee \& Markham, 2015; Stride \& Lee, 2007). Among the commercial aversions are the difficulty of an NPO to see itself as a social business (B14), to adopt brand strategies (B23) and to implement strategic projects (B17), characteristics that seem to be related to the attributions of NPO managers, given that the level of brand orientation in an NPO is related to the managers' practices and behaviors (Hankinson, 2002). NPO resistance to thinking of themselves as brands (B21) makes it difficult for them to be brand-oriented, given Hankinson's (2000) definition of NBO, which is how much the NPO sees itself as a brand.

The F3 construct, barriers to donation, includes variables that prove to be barriers to the donation of money, which reinforces a lack of financial resources (Wong \& 
Merrilees, 2005). These barriers include a lack of confidence in the NPO (B2), and an NPO's credibility is noted by Mainardes et al. (2017) as one of the motivators of money donation in Brazil. People's lack of interest (B11), aligned with the lack of a culture of giving (B1), appear to be barriers, despite the recent improvement of the last variable, mainly attributed to the global pandemic (IDIS, 2020). This improvement may be related to the lack of continuity of donations (B4), that is, a donation is motivated when there is a need for NPOs (Mainardes et al., 2017; Sepulcri, Mainardes, \& Pascuci, 2020), without creating awareness among donors about the cause, who end up discontinuing their donations. This phenomenon may be linked to the difficulty of the NPO in communicating the social result achieved (B12) when making use of these donations.

Finally, variables linked to the economic context were grouped in F4, given the peculiarities of emerging markets, which generally experience greater economic and political instability (Sheth, 2011). The oscillation between boom periods and financial crisis is not uncommon (B15, B20), especially in Brazil, and can directly affect the level of donations to the NPO. The dependence of many NPOs, especially Brazilian NPOs, on public power or political relations (Sepulcri, Mainardes, \& Pascuci, 2020) encourages "unbranded competition" (Sheth, 2011), often creating an unfavorable context for the development of NPO brands (B26).

In short, barriers are seen as a higher-order reflective construct, given that, together, the constructs found can affect both the relationship between the background and the implementation of NBO in an emerging country, as it makes it difficult for NBO to have an effect for the (consequential) NPO, weakening these relationships (Sepulcri, Mainardes, \& Pascuci, 2020). The NBO barriers construct is thus composed of four reflective lower-order constructs, called communication challenges, commercial aversion, barriers to donation, and economic context.

\section{Discussions}

When grouping and systematizing non-profit brand orientation, two aspects are central to brand creation, brand development, and protection (Urde, 1999). The first aspect is the cause, which is the reason for the existence of the NPO (Hankinson, 2000; Sepulcri, Mainardes, \& Pascuci, 2020), followed by brand communication in a consistent and aligned way for the various stakeholders. The creation and development of the NPO brand therefore starts from the cause defended by the organization, its mission, and values, which must be represented through the various symbols associated with the brand, such as name and logo (Hankinson, 2000), and must be communicated consistently to the various stakeholders, whether internal or external to the NPO (Ewing \& Napoli, 2005; Hankinson, 2000).

It is worth mentioning that the demonstration of the results obtained, and the transparency of the financial resources are variables that seem to be related to the construction of trust in the NPO brand, which is needed to foster donations and partnerships (Laidler Kylander \& Simonin, 2009; Mainardes et al., 2017), seen in this study as a consequent of NBO. The development of the brand internally involves the 
training given to the organization's staff, who must disseminate the understanding of the brand (King \& Grace, 2010; Liu et al., 2017).

Three constructs emerged from the data as antecedents to NBO in an emerging country: organizational factors, market factors, and action. Regarding organizational factors, it is worth noting that, in addition to the organizational culture, management, and organization structure (Evans et al., 2012; Hankinson, 2001), an element of the antecedents is the professionalization of staff as a whole. It is thus assumed that a management committed to the development of the brand drives the organization in this direction. Staff training affects the delivery of quality products and services, which, by being aligned with the NPO brand, help to develop it consistently. Competition with other organizations is one of the market factors proposed by Urde (1994) as an antecedent to brand orientation, and, considering the particularities of the non-profit sector, this competition includes competition for volunteers and partners who support the activities of the NPO (Hankinson, 2000). That is, the more NPOs need to differentiate themselves, and stand out from each other to compete for resources, the more they tend to develop their brands. Finally, it is worth highlighting the importance of understanding the cause in the construct action, in order to create and develop a brand that reflects the cause (Hankinson, 2001), and that is associated with the social benefits achieved by the organization (Venable et al., 2005). The more the NPO can show the results achieved, the more it is acknowledged for its performance, which is represented by its brand (Sepulcri et al.,2020b).

With regard to the consequents of $\mathrm{NBO}$, it is clear that the fundraising construct aggregates variables that are not only related to direct donations (which may be monetary or not), but from different means of obtaining resources from different stakeholders (Apaydın, 2011). Obtaining these resources is related to the NPO's brand image (Michel \& Rieunier, 2012), which is generated from the consistent development of NPO brands. In addition to for-profit companies (Hankinson, 2000), NPOs can also partner with each other and help each other, especially when they share some aspect of their cause, such as, for example, the defense of animals, social minorities, or the environment. It is worth emphasizing the importance of alignment between the organizations' brands (da Silva et al., 2020b; Hankinson, 2000; Tilley, 1999) in any type of partnership. Alignment with the brand can be applied to staff, creating emotional bonds, engagement, a sense of purpose, and alignment with brand values (Curran et al., 2016; Hankinson, 2000; Liu et al., 2015, 2017).

Finally, we argue that the performance of the NPO can influence society by narrowing the relationship between the NPO and academia, achieved by developing the NPO brand. This relationship can enable the generation of data that can support other non-profit organizations and the direction of public policies, the latter being recognized as one of the roles of an NPO (Apaydın, 2011; Hankinson, 2000). We therefore suggest that by being brand oriented, NPOs can consistently represent and communicate their causes, achieving greater recognition of their brands, attracting resources and partnerships, engaging their employees, and leveraging influence in society. These relationships need to be further tested.

Despite the importance of communication for NBO, aligning communication with the various stakeholders is a challenge (Hankinson, 2000). Even the largest NPOs seem to face this difficulty, which can be due to the diversity of actions 
that these organizations carry out, as reported by Sepulcri, Mainardes, and Pascuci (2020). When motivated by the perception of the need for an NPO (Mainardes et al., 2017), however, some donors may fail to contribute to an NPO that is seen as "famous" or as not needing further donations. These factors may contribute to NPOs being afraid to promote their brands, which may also be linked to the difficulty that NPOs have in demonstrating their results.

Added to this, there is apprehension about NPOs being seen as commercial, and thus neglecting brand strategies (Stride \& Lee, 2007). The barriers found may lead the non-profit to not seek to implement NBO, and/or has difficulties accomplishing its consequent, since, as it becomes recognized, some stakeholders may stop supporting the NPO. Finally, we found that the lack of a donation culture in a population seems to negatively influence people to start donating or to continue donating, and that the political and economic context can also create more hostile environments for the development of NPO brands (Casey, 2016).

In an emerging country, NBO is based on the cause of a NPO and on consistent communication with the various stakeholders. As antecedents, in addition to the internal context of the organization and the market in which it is inserted (Evans et al., 2012; Hankinson, 2000, 2001; Urde, 1994), is the need for the NPO to demonstrate its social performance, that is, to obtain a "social license" (Sepulcri, Mainardes, \& Pascuci, 2020) where it operates, which can be achieved by developing the NPO brand, and therefore, by implementing an NBO strategy.

Brand development through the implementation of NBO means that an NPO benefits from increased fundraising (monetary or not), facilitating partnerships, improving relationships with staff, and greater social influence. By consistently communicating their brands, and linking their brands to their causes, missions, values, results and transparency in the use of resources, NPOs create a positive image of their brands, and tend to attract people to support them. Barriers related to an NPO's communication with stakeholders include the NPO's fear of being seen as too commercial, and the lack of culture and continuity of donations and the economic context can hamper both the implementation of NBO and the achievement of its benefits. Figure 1 synthesizes the constructs and the relationships proposed between them.

\section{Conclusions}

This study sought to group and systematize the elements that comprise non-profit brand orientation in an emerging country, as well as the elements that precede nonprofit brand orientation, and the consequents and barriers to the implementation of this strategy, within the context of a Brazilian NPO. Considering the results of the analyses, we conclude that NBO in an emerging country is a higher-order reflective construct composed of two lower-order reflective constructs called communication and cause. The three reflective lower-order constructs found in this work as antecedents to NBO were organizational factors, market factors, and action. As a consequent of NBO, we found four lower-order reflective constructs called fundraising, partnerships, staff relationships, and social influence. Finally, we understand that barriers to NBO constitute a higher-order reflective construct, composed of four reflective 
lower-order constructs, called communication challenges, commercial aversion, barriers to donation, and economic context.

If there are market factors, mainly linked to competition for resources, and management that understands the work of the NPO and can implement brand strategies, adding the need for NPO to show its performance to society, then the NPO tends to develop NBO. Such a strategy is potentially related to the organization's cause, that is, to the social problem it seeks to address, and in the correct communication of its cause, values, mission, and results to the various stakeholders, aligned with transparency in the use of financial resources.

As a consequence of the development of NBO, NPOs tend to find it easier to raise funds (monetary or not) and to establish partnerships (either with the private sector or with other NPOs). When implementing NBO, NPOs tend to improve relationships with their staff and increase their social influence, generating greater gains for the defended cause. However, the difficulties in communicating consistently, the fear of adopting brand practices that sound very commercial, the lack of a culture of donation from society, aligned with inconsistency in donations, and economic and political issues, can be barriers that NPOs need to overcome in order to implement NBO and achieve the consequent benefits of this strategic orientation. Especially, NPOs need to be careful to not transmit a brand message that could be associated with the main objective of sale and, consequently, profits. This "commercial goal" can generate a resistance to cooperation internal and externally. The brand message should be associated with the social transformation that the NPO wants to see in the community.

This study contributes to the current literature by proposing a means that measures NBO in an emerging country, as well as its antecedents, consequents, and barriers. Unlike the proposal by Ewing and Napoli (2005), NBO in an emerging country is based mainly on the creation and development of the brand based on the cause advocated by the organization, and on the consistent communication of the brand to the various stakeholders. The construct action stands out as an antecedent. That is, in addition to the marketing and organizational aspects already discussed in the literature (Casidy, 2013; Ewing \& Napoli, 2005; Hankinson, 2000, 2001; Urde, 1994), NBO also seems to be driven by the need for NPO to demonstrate a social impact where it operates, that is, to use the NPO brand to be recognized as an NPO that "makes a difference" in each cause.

In addition to information about improving fundraising, facilitating partnerships and engaging staff (Apaydın, 2011; Curran et al., 2016; Hankinson, 2000; Liu et al., 2015, 2017), the results of the research added, as variables that measure the consequences of NBO, the facilitation of partnerships between NPOs, an increase in the social influence of NPOs via partnership with academia, and also the influence of brand in volunteer retention. Finally, the study contributes to the measurement of barriers to NBO that go beyond political and economic aspects in an emerging country (Casey, 2016), and are also related to the lack of a donation culture, and the lack of continuity of donations, which aggravates the lack of financial resources for NPOs (Wong \& Merrilees, 2005).

There are limitations to the study. We used a non-probabilistic sampling, which does not allow generalization to the entire NPO population, and therefore probabilistic sampling should be used in future studies in order to generalize the results. The constructs are based on qualitative exploratory research and nether the constructs nor the model were tested, so, other constructs can also be associated to NBO, and other items can be 
found to measure them. The study was based on only one emerging country (Brazil), with a concentration of respondents in the southeast region, and there could be differences in other countries with similar economies, and even within the Brazilian context, given the country's proportions and different realities in the regions. We therefore recommend that the constructs presented here be applied and compared in different contexts and even compared between sectors of non-profit organizations.

Future studies could verify the relationships between the constructs found in the Brazilian context, or in different emerging economies. Although the emerging countries share characteristics, the peculiarities of them open an opportunity for studies that compare one or more countries. In addition to the issues given by the market, and the internal aspects of the organization, our findings indicate the need for NPOs to demonstrate the impacts of its actions in society, which is represented by the construct named action, something to be deepened in future studies.

This relationship between the level of involvement of the NPO with society and the perception of the social impact and importance of the organization by society, especially those that are around or that are directly impacted by the organization, seems to drive brand orientation, being an interesting subject to be studied in the future. As recently is discussed the "social license" to for-profits operates (ESG discussions), is expected for nonprofits to have an even bigger commitment and impact in society. This aspect can be deeper explored in future research. Also, other constructs can be investigated as antecedents to NBO and consequent to NBO, such as financial metrics, and socioeconomic and market development, which corroborate the idea of increasing fundraising, increasing social influence, and strengthening the brand. The interaction of NBO with other strategic orientations (Urde et al., 2013) applied to the third sector could also be explored.

\section{Practical implications}

Some donations are motivated by an NPO's perceived need (Mainardes et al., 2017), which can lead NPOs to focus more on asking for the resources they need rather than promoting their brands and social results. This study can help managers of non-profit organizations in emerging countries to understand the NBO strategy and the benefits of its implementation, thus developing NPO brands and helping to reach their social missions.

As a practical recommendation, the NPO needs to work in a deep understanding of term brand and the strategic use of this brand, as the concept still seems to be incipient in the nonprofit context (Stride \& Lee, 2007). And the marketers need to take care of the strategies used to convince the donors, volunteers, and other stakeholders to collaborate with the organization, as this communication needs to convince all of them by the purpose, the cause, instead of reflecting an image that NPO just wants to raise more money, what we called "commercial practices". So, with more efficient NPO, society as a whole therefore wins, by gaining access to services and products, as NPOs fill gaps not served by the government, and help develop society. 


\section{Appendix}

Table 1 Sample characterization

\begin{tabular}{|c|c|c|c|c|}
\hline Characteristic & Definition & Quant. & $\%$ & $\%$ accumulated. \\
\hline \multirow{5}{*}{$\begin{array}{l}\text { Importance of } \\
\text { NPOs }\end{array}$} & Are not important & 2 & $0.90 \%$ & $0.90 \%$ \\
\hline & Are of little importance & 3 & $1.35 \%$ & $2.24 \%$ \\
\hline & Are important & 41 & $18.39 \%$ & $20.63 \%$ \\
\hline & Are very important & 73 & $32.74 \%$ & $53.36 \%$ \\
\hline & Are extremely important & 104 & $46.64 \%$ & $100.00 \%$ \\
\hline \multirow{6}{*}{$\begin{array}{l}\text { Time of involve- } \\
\text { ment with the } \\
\text { NPOs }\end{array}$} & Less than 1 year & 18 & $8.07 \%$ & $8.07 \%$ \\
\hline & 1 to 2 years & 23 & $10.31 \%$ & $18.39 \%$ \\
\hline & 2 to 5 years & 37 & $16.59 \%$ & $34.98 \%$ \\
\hline & 5 to 10 years & 24 & $10.76 \%$ & $45.74 \%$ \\
\hline & More than 10 years & 88 & $39.46 \%$ & $85.20 \%$ \\
\hline & Never donated / participated & 33 & $14.80 \%$ & $100.00 \%$ \\
\hline \multirow{7}{*}{$\begin{array}{l}\text { Frequency in NPO } \\
\text { activities }\end{array}$} & Weekly & 29 & $13.00 \%$ & $13.00 \%$ \\
\hline & Monthly & 45 & $20.18 \%$ & $33.18 \%$ \\
\hline & Annually & 18 & $8.07 \%$ & $41.26 \%$ \\
\hline & Sporadically & 44 & $19.73 \%$ & $60.99 \%$ \\
\hline & Never donate/participate & 20 & $8.97 \%$ & $69.96 \%$ \\
\hline & I am employed by a non-profit organization & 53 & $23.77 \%$ & $93.72 \%$ \\
\hline & Other & 14 & $6.28 \%$ & $100.00 \%$ \\
\hline \multirow{8}{*}{$\begin{array}{l}\text { Distance from } \\
\text { NPOs }\end{array}$} & They are near my home & 48 & $21.52 \%$ & $21.52 \%$ \\
\hline & They are near my work & 21 & $9.42 \%$ & $30.94 \%$ \\
\hline & $\begin{array}{l}\text { In the municipality where I live, but not } \\
\text { close to my home or work }\end{array}$ & 74 & $33.18 \%$ & $64.13 \%$ \\
\hline & $\begin{array}{l}\text { In the state where I live, but outside the } \\
\text { municipality where I live or work }\end{array}$ & 29 & $13.00 \%$ & $77.13 \%$ \\
\hline & $\begin{array}{l}\text { NPOs are not located in the state in which I } \\
\text { live or work, but operate in Brazil }\end{array}$ & 9 & $4.04 \%$ & $81.17 \%$ \\
\hline & $\begin{array}{l}\text { NPOs do not operate in Brazil, that is, they } \\
\text { are exclusively foreign }\end{array}$ & 1 & $0.45 \%$ & $81.61 \%$ \\
\hline & I do not participate/donate & 27 & $12.11 \%$ & $93.72 \%$ \\
\hline & Other & 14 & $6.28 \%$ & $100.00 \%$ \\
\hline \multirow{5}{*}{$\begin{array}{l}\text { How many NPOs } \\
\text { he/she knows }\end{array}$} & Up to 2 & 50 & $22.42 \%$ & $22.42 \%$ \\
\hline & Between 3 and 6 & 107 & $47.98 \%$ & $70.40 \%$ \\
\hline & Between 7 and 9 & 36 & $16.14 \%$ & $86.55 \%$ \\
\hline & Between 10 and 12 & 6 & $2.69 \%$ & $89.24 \%$ \\
\hline & More than 12 & 24 & $10.76 \%$ & $100.00 \%$ \\
\hline \multirow[t]{2}{*}{ Gender } & Male & 92 & $41.26 \%$ & $41.26 \%$ \\
\hline & Female & 131 & $58.74 \%$ & $100.00 \%$ \\
\hline \multirow[t]{5}{*}{ Age } & Up to 20 years of age & 2 & $0.90 \%$ & $0.90 \%$ \\
\hline & Between 21 and 30 years of age & 53 & $23.77 \%$ & $24.66 \%$ \\
\hline & Between 31 and 40 years of age & 74 & $33.18 \%$ & $57.85 \%$ \\
\hline & Between 41 and 50 years of age & 52 & $23.32 \%$ & $81.17 \%$ \\
\hline & Above 50 years & 42 & $18.83 \%$ & $100.00 \%$ \\
\hline
\end{tabular}


Table 1 (continued)

\begin{tabular}{|c|c|c|c|c|}
\hline Characteristic & Definition & Quant. & $\%$ & $\%$ accumulated. \\
\hline \multirow[t]{5}{*}{ Marital status } & Single & 76 & $34.08 \%$ & $34.08 \%$ \\
\hline & Married & 123 & $55.16 \%$ & $89.24 \%$ \\
\hline & Divorced & 16 & $7.17 \%$ & $96.41 \%$ \\
\hline & Widowed & 4 & $1.79 \%$ & $98.21 \%$ \\
\hline & Other & 4 & $1.79 \%$ & $100.00 \%$ \\
\hline \multirow[t]{5}{*}{ Education level } & Elementary education or less & 6 & $2.69 \%$ & $2.69 \%$ \\
\hline & High school/technical & 28 & $12.56 \%$ & $15.25 \%$ \\
\hline & University education & 63 & $28.25 \%$ & $43.50 \%$ \\
\hline & Postgraduate studies & 122 & $54.71 \%$ & $98.21 \%$ \\
\hline & Other & 4 & $1.79 \%$ & $100.00 \%$ \\
\hline \multirow[t]{6}{*}{ Region of Brazil } & Northeast & 16 & $7.17 \%$ & $7.17 \%$ \\
\hline & North & 9 & $4.04 \%$ & $11.21 \%$ \\
\hline & Midwest & 5 & $2.24 \%$ & $13.45 \%$ \\
\hline & Southeast & 187 & $83.86 \%$ & $97.31 \%$ \\
\hline & South & 6 & $2.69 \%$ & $100.00 \%$ \\
\hline & Abroad & 0 & $0.00 \%$ & $100.00 \%$ \\
\hline \multirow[t]{7}{*}{ Occupation } & Student & 20 & $8.97 \%$ & $8.97 \%$ \\
\hline & For-profit private sector employee & 51 & $22.87 \%$ & $31.84 \%$ \\
\hline & Third sector employee & 35 & $15.70 \%$ & $47.53 \%$ \\
\hline & Public sector employee & 41 & $18.39 \%$ & $65.92 \%$ \\
\hline & Self-employed & 40 & $17.94 \%$ & $83.86 \%$ \\
\hline & Retired & 10 & $4.48 \%$ & $88.34 \%$ \\
\hline & Other & 26 & $11.66 \%$ & $100.00 \%$ \\
\hline \multirow[t]{6}{*}{ Monthly income } & Up to BRL 2000.00 & 49 & $21.97 \%$ & $21.97 \%$ \\
\hline & Between BRL 2001.00 and BRL 5000.00 & 81 & $36.32 \%$ & $58.30 \%$ \\
\hline & Between BRL 5001.00 and BRL 8000.00 & 49 & $21.97 \%$ & $80.27 \%$ \\
\hline & Between BRL 8001.00 and BRL 12,000.00 & 20 & $8.97 \%$ & $89.24 \%$ \\
\hline & $\begin{array}{l}\text { Between BRL 12,001.00 and BRL } \\
15,000.00\end{array}$ & 12 & $5.38 \%$ & $94.62 \%$ \\
\hline & Above BRL 15,000.00 & 12 & $5.38 \%$ & $100.00 \%$ \\
\hline
\end{tabular}

Research data 


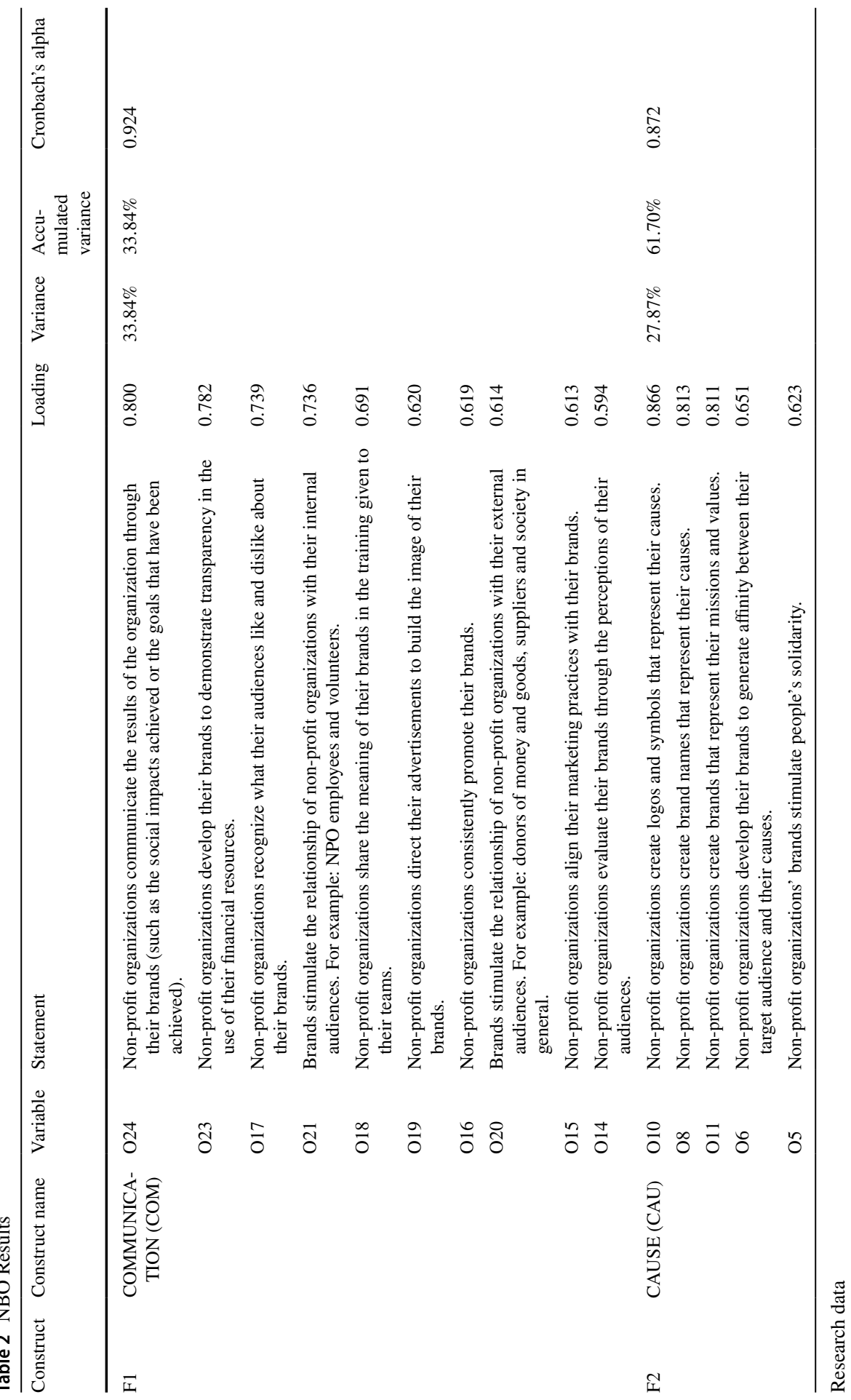




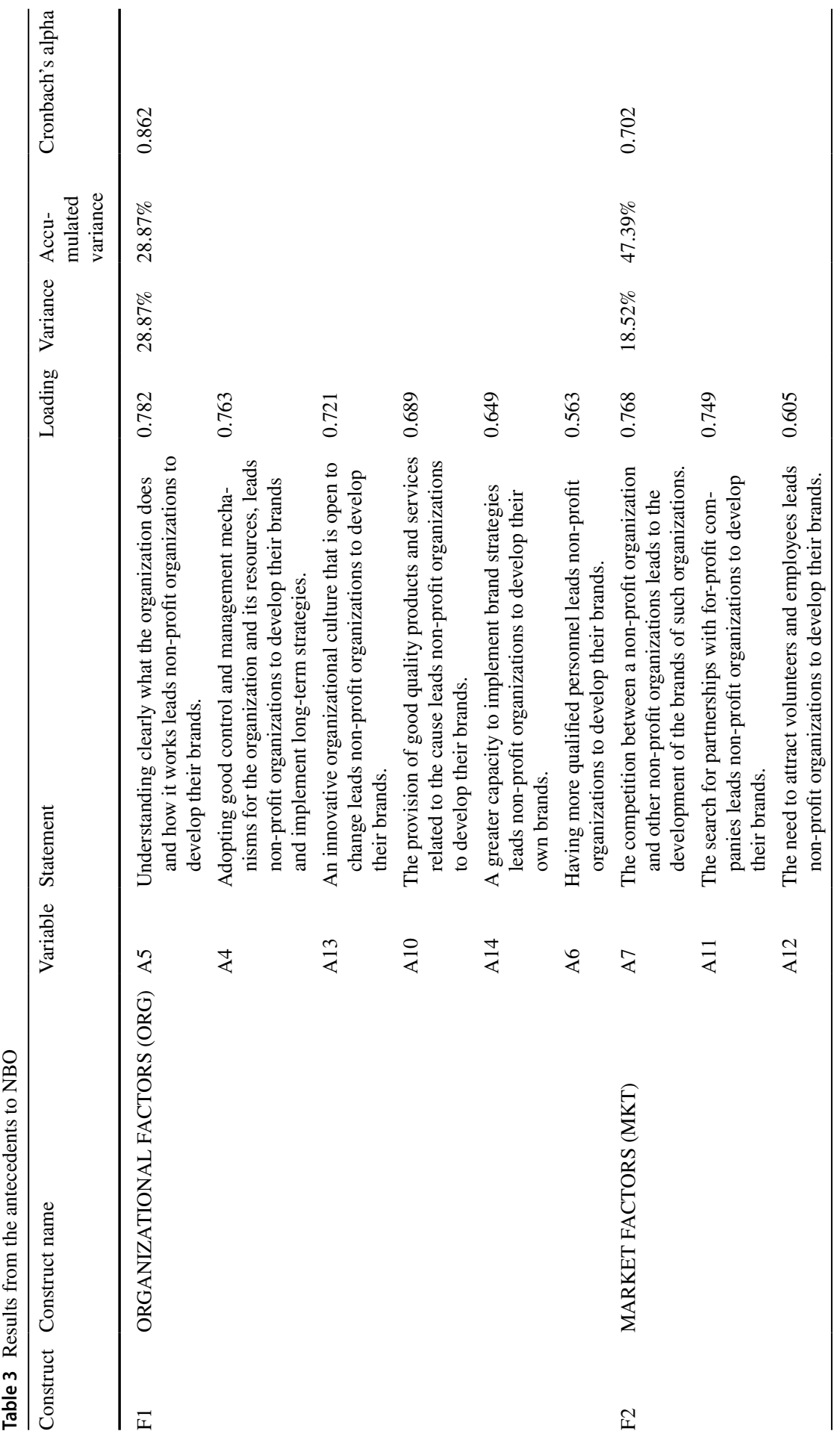




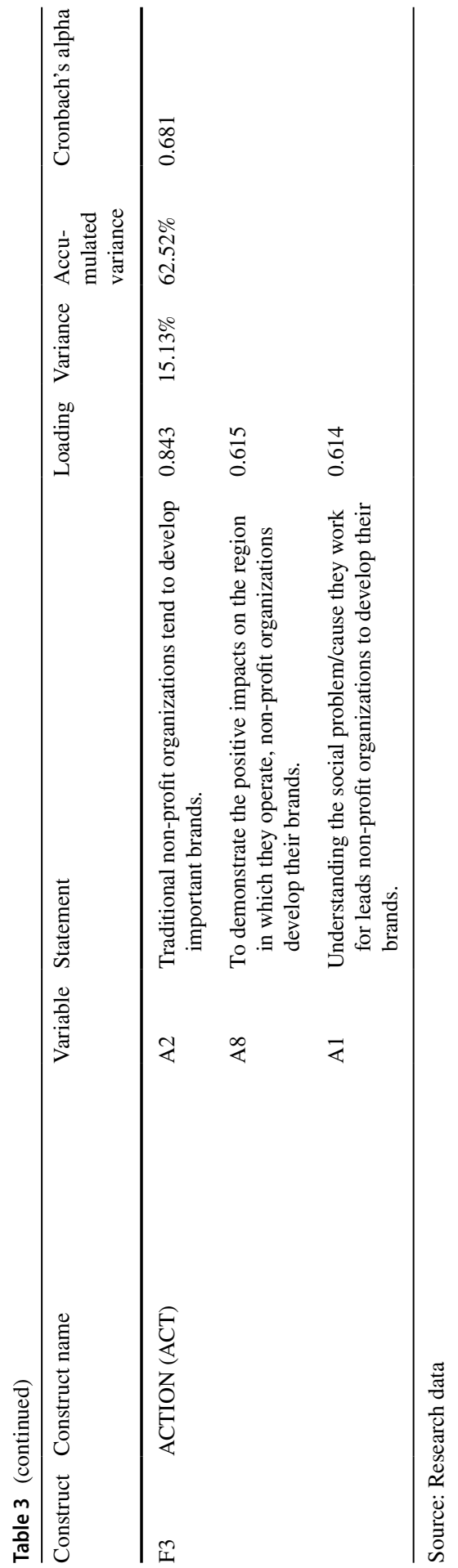




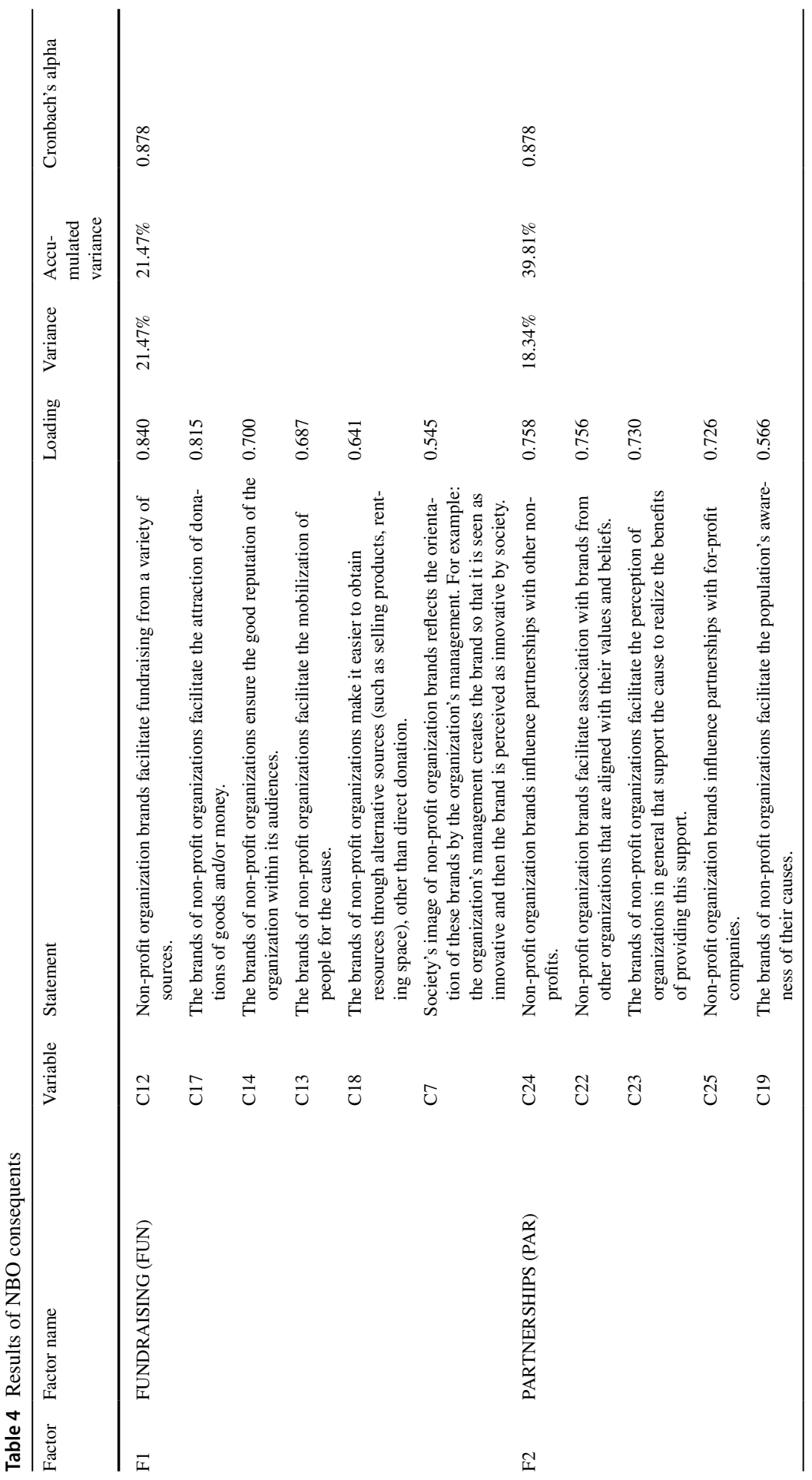




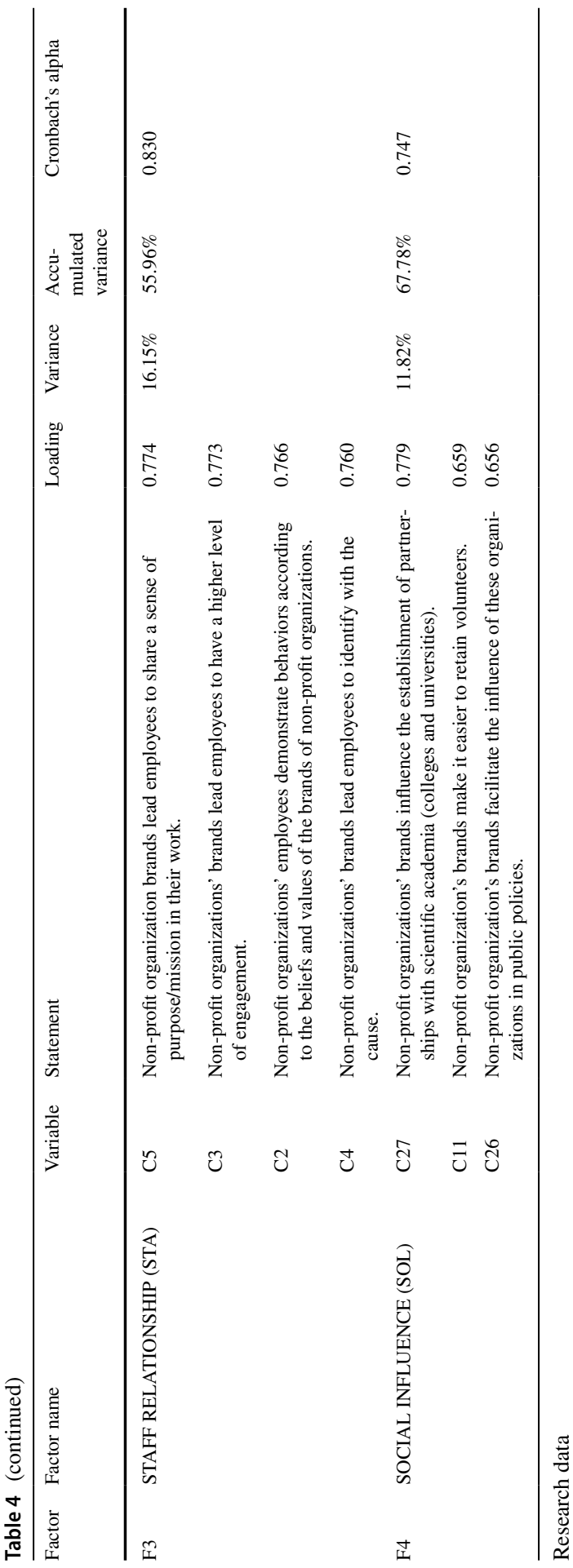




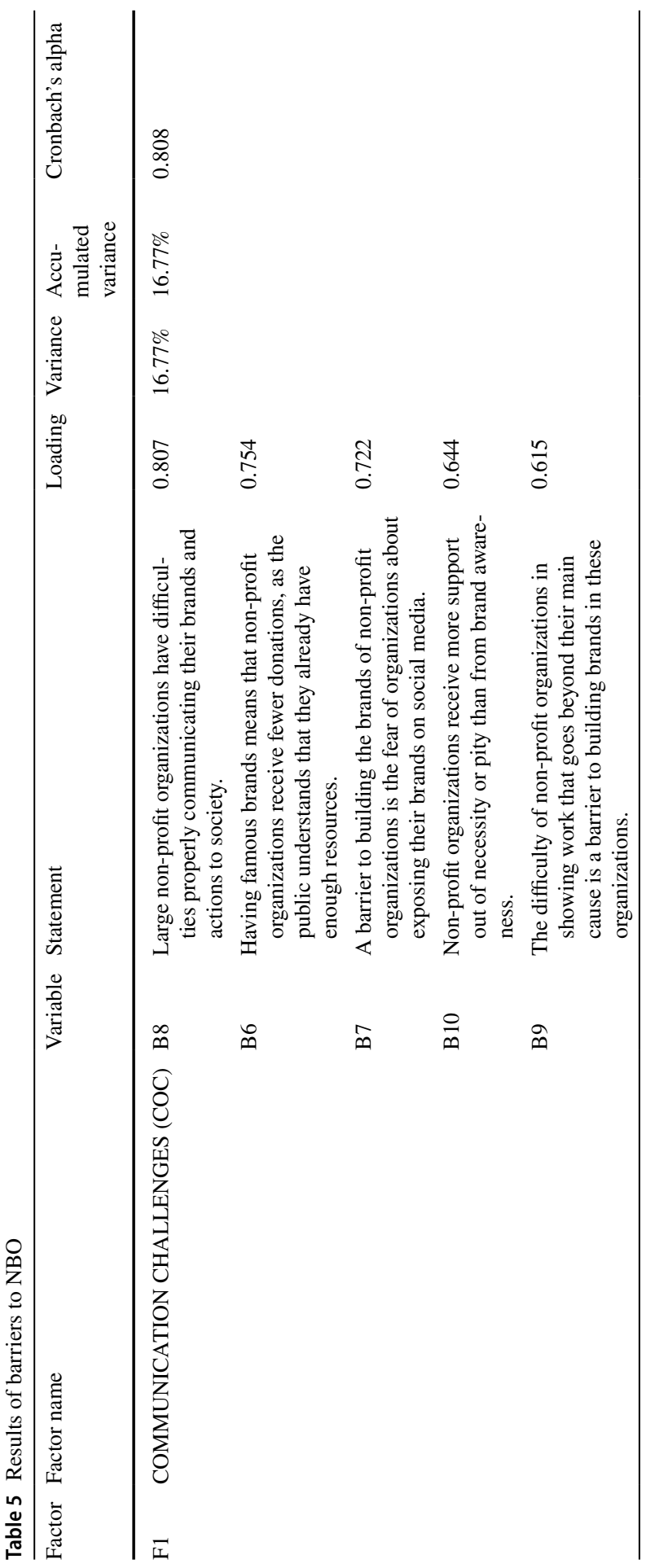




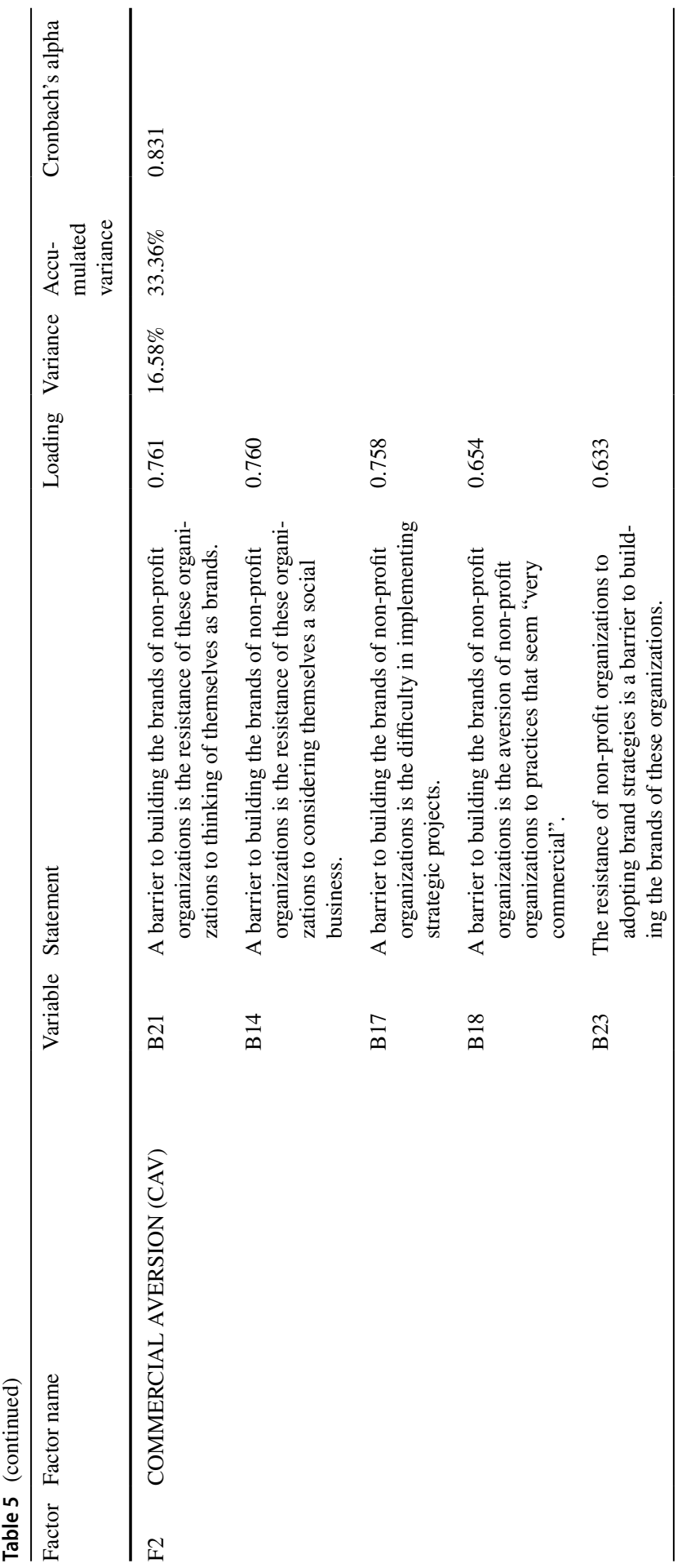




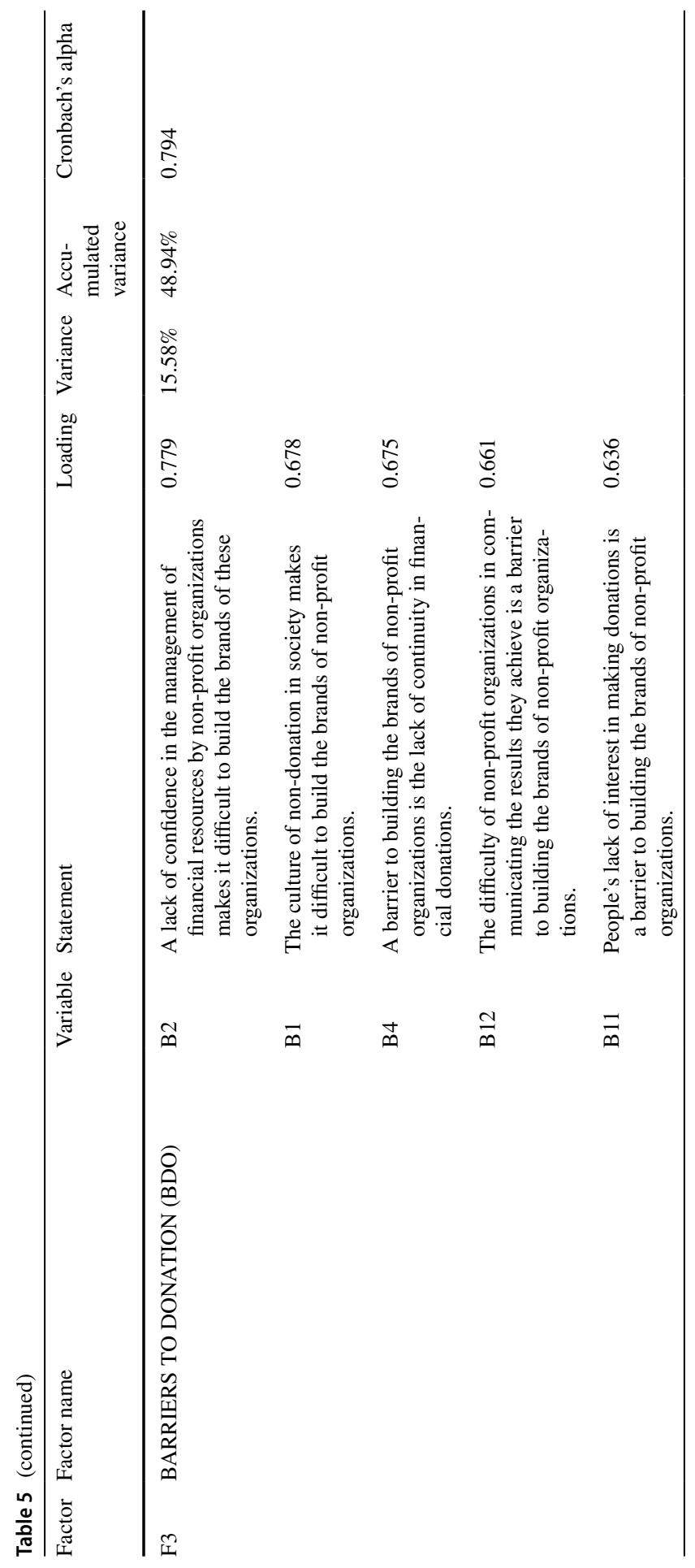




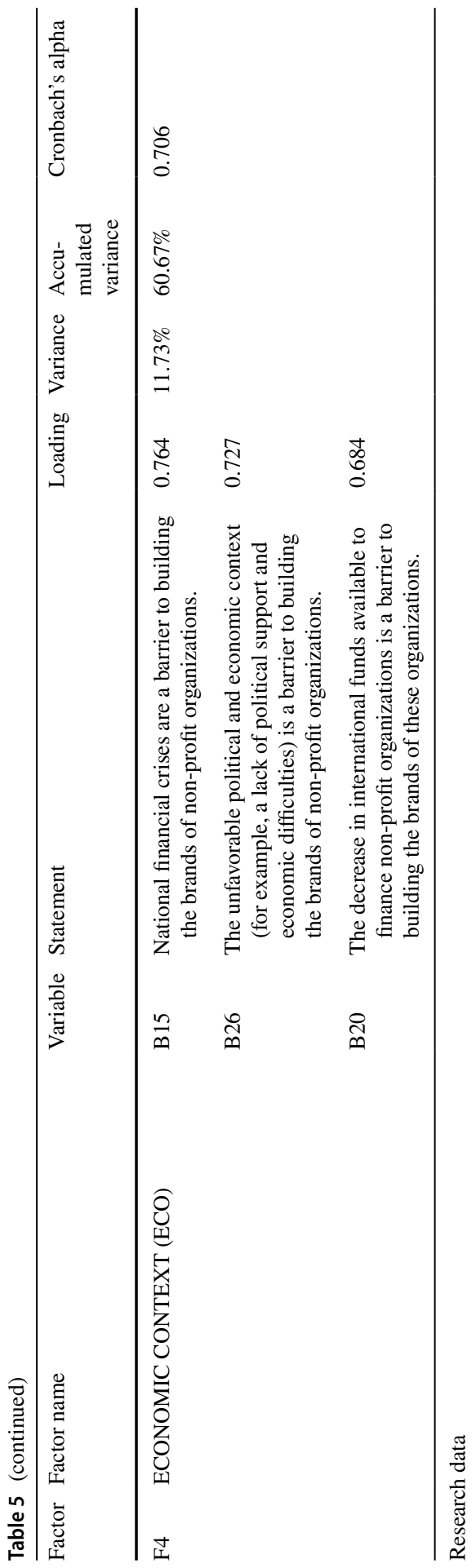




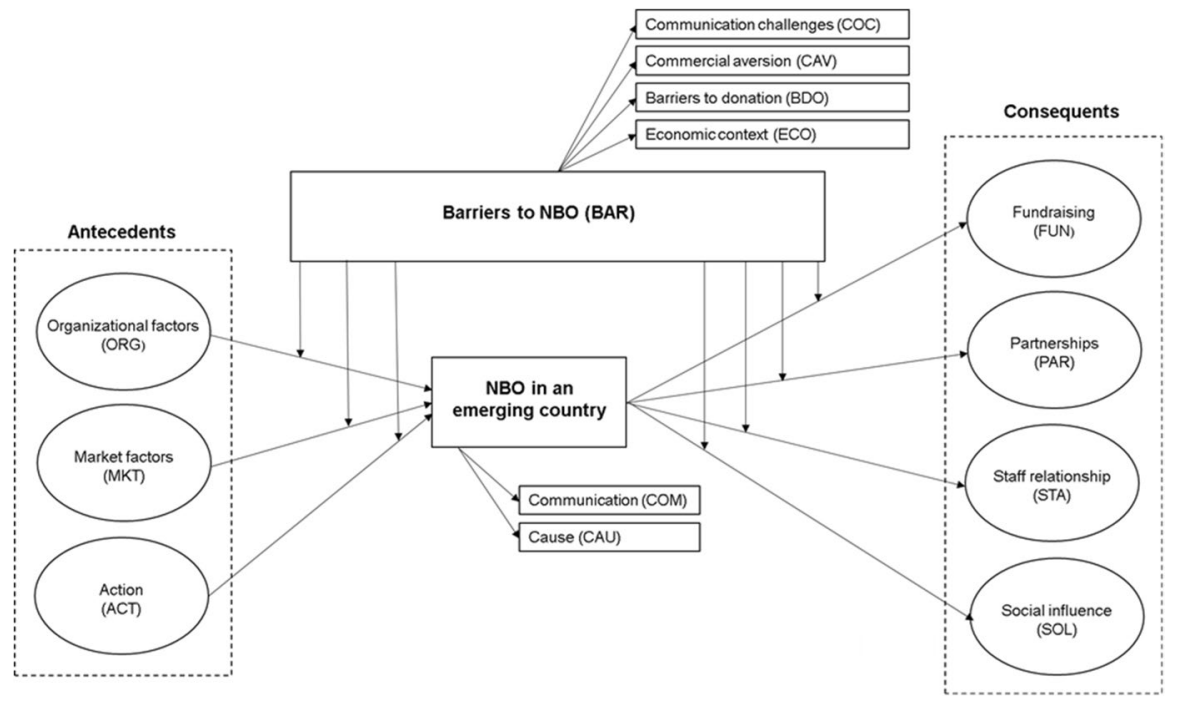

Fig. 1 Constructs and relations. Source: Own elaboration. Note: "NBO in an emerging country" and "Barriers to NBO" are higher-order constructs. "Antecedents" and "Consequents" are a set of lowerorder constructs 


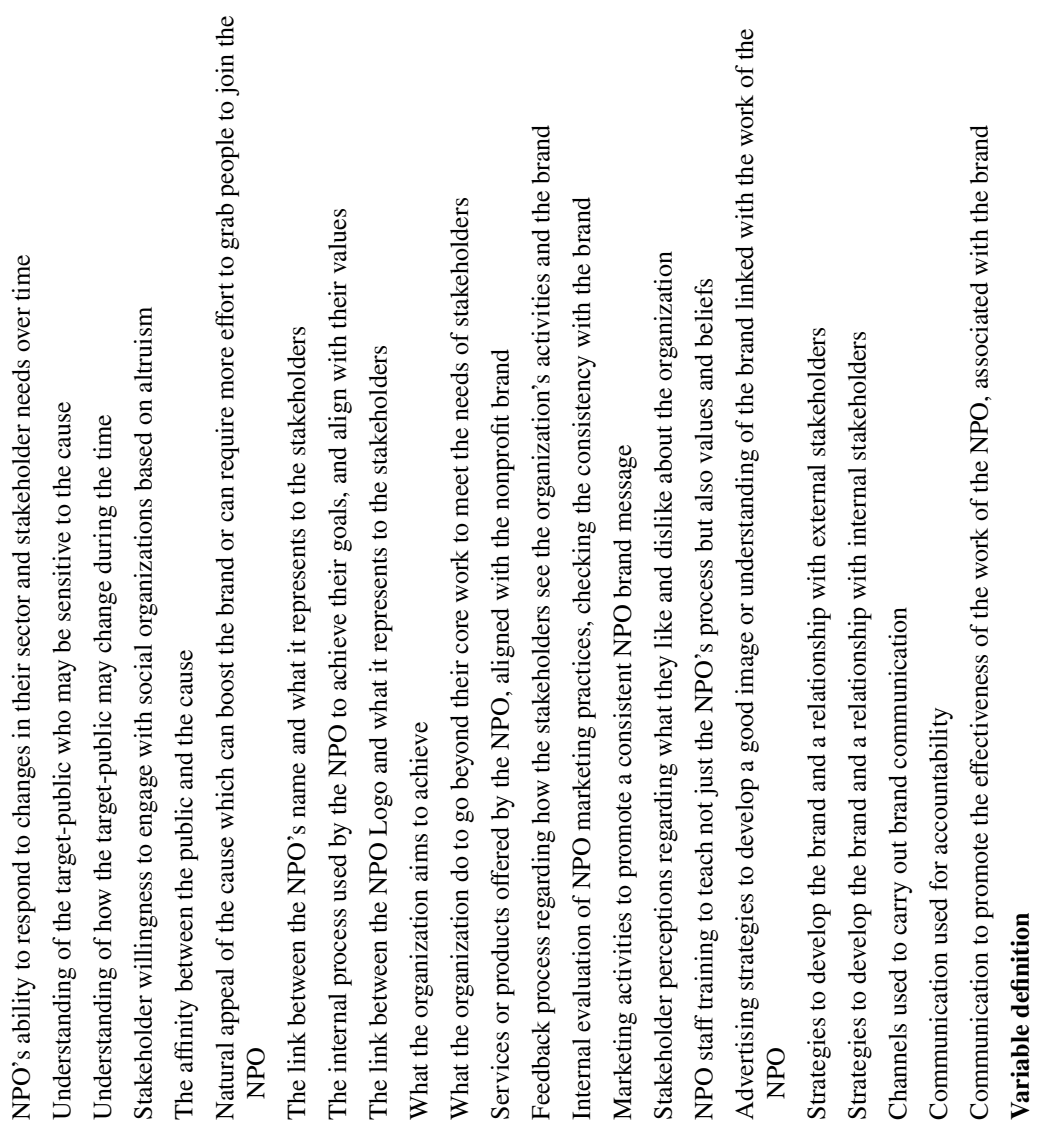



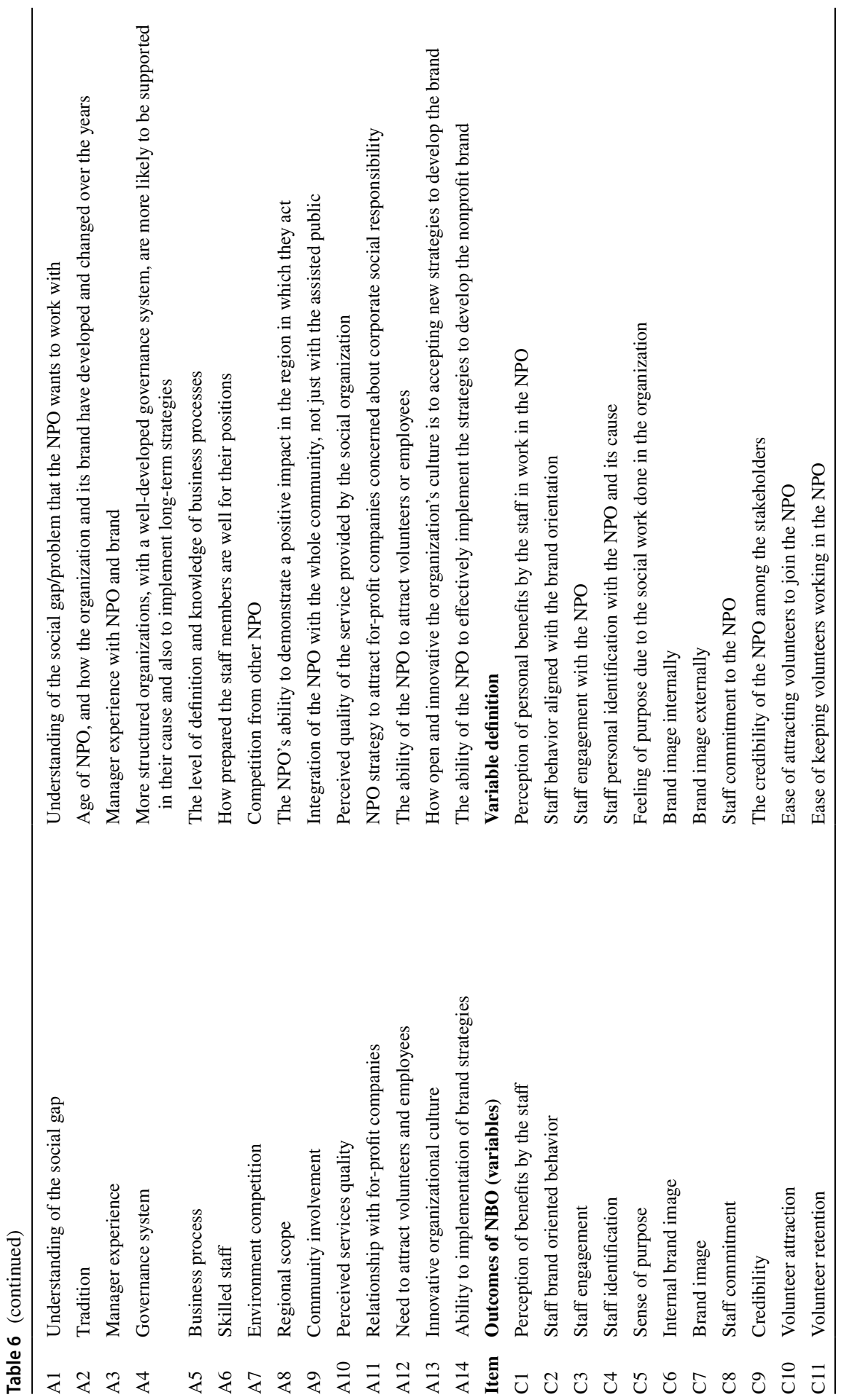


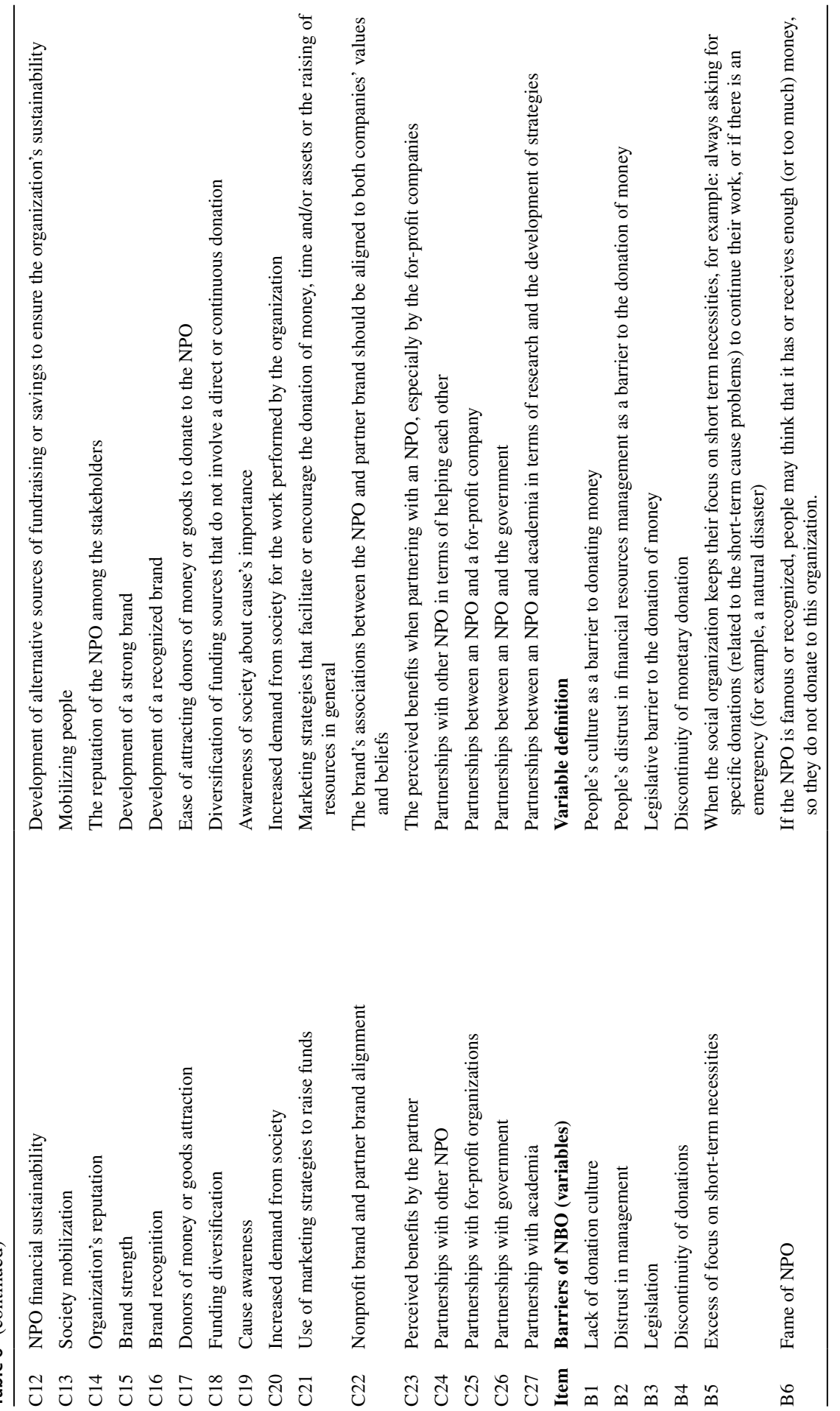




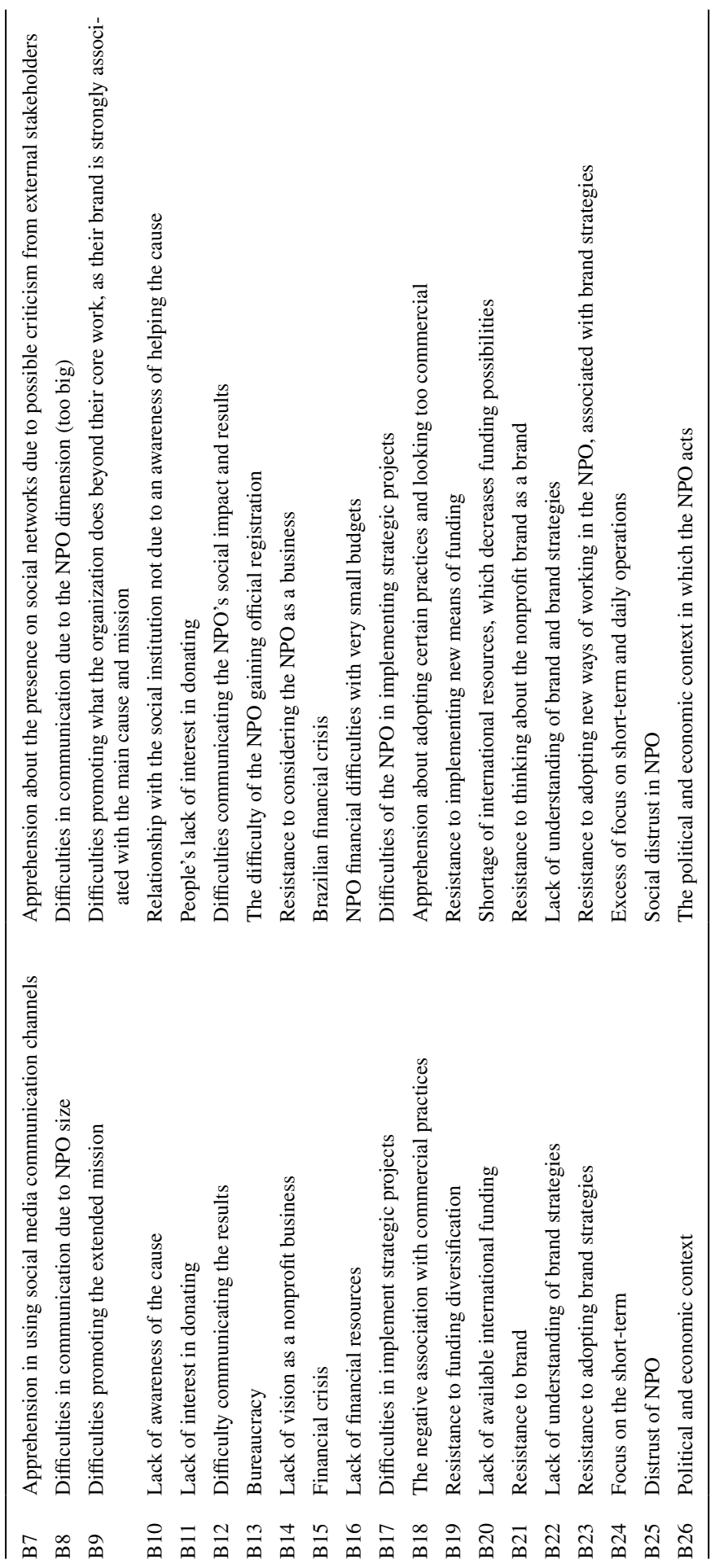


Funding This research was supported by Brazilian National Council for Scientific and Technological Development (CNPq/Brazil), project 304209/2018-0, by Foundation for Research Support of Espírito Santo (FAPES/Brazil), projects 84513772 (599/2018), 85395650 (228/2019) and 30007011003P2 (02/2018), by Coordination for the Improvement of Higher Education Personnel (CAPES/Brazil), project 88881.361587 (2019/01), by Portuguese Science Foundation (FCT/Portugal) through NECE (Núcleo de Estudos em Ciências Empresariais), project UID/GES/04630/2020, and by IFTS (Instituto Fucape de Tecnologias Sociais), project 2021-2024.

\section{Declarations}

Conflict of interest On behalf of all authors, the corresponding author states that there is no conflict of interest.

\section{References}

Andreasen, A. R. (2012). Rethinking the relationship between social/nonprofit marketing and commercial marketing. Journal of Public Policy \& Marketing, 31(1), 36-41.

Anees-ur-Rehman, M., Wong, H. Y., \& Hossain, M. (2016). The progression of brand orientation literature in twenty years: A systematic literature review. Journal of Brand Management, 23(6), 612-630.

Apaydin, F. (2011). A proposed model of antecedents and outcomes of brand orientation for nonprofit sector. Asian Social Science, 7(9), 194-202.

Artemisia. (2020). Quem somos. Retrieved on December 15, 2020, from https://artemisia.org.br/quems omos/.

Baumgarth, C., \& Schmidt, M. (2010). How strong is the business-to-business brand in the workforce? An empirically-tested model of 'internal brand equity' in a business-to-business setting. Industrial Marketing Management, 39(8), 1250-1260.

Bevilacqua, R., Freitas, V., \& Paula, V. (2020). Innovation and brands: The managers' perspective in a multiple case study in a Brazilian region. Brazilian Business Review, 17(6), 686-705.

Boateng, G. O., Neilands, T. B., Frongillo, E. A., Melgar-Quiñonez, H. R., \& Young, S. L. (2018). Best practices for developing and validating scales for health, social, and behavioral research: A primer. Frontiers in Public Health, 6(149), 1-18.

Boenigk, S., \& Becker, A. (2016). Toward the importance of nonprofit brand equity: Results from a study of German nonprofit organizations. Nonprofit Management \& Leadership, 27(2), 181-198.

Brazilian Association of Fund Raisers. (2020). Doações para combater o impacto do coronavírus ultrapassam 6 bilhões de reais no Brasil. Retrieved on 28 October, 2020, from https://capta dores.org.br/2020/07/21/doacoes-para-combater-o-impacto-do-coronavirus-ultrapassam-6-bilho es-de-reais-no-brasil/

Brazilian Institute of Statistical Geography. (2020). Pesquisa nacional por amostra de domicílio contínua. Rendimento de todas as fontes 2019. PNAD Contínua (ISBN 978-65-87201-08-5). Retrieved on 12 December, 2020, from https://biblioteca.ibge.gov.br/index.php/biblioteca-catalogo?view= detalhes\&id=2101709

Candler, G., \& Dumont, G. (2010). A non-profit accountability framework. Canadian Public Administration, 53(2), 259-279.

Cant, M. C., Wiid, J. A., \& Hung, Y. T. (2013). The importance of branding for south African SMEs: An exploratory study. Corporate Ownership and Control, 11(1), 735-744.

Casey, J. (2016). Comparing nonprofit sectors around the world: What do we know and how do we know it? The Journal of Nonprofit Education and Leadership, 6(3), 187-223.

Casey, J. (2020). Comparing third sector Expansions ${ }^{1}$. Journal of Comparative Policy Analysis: Research and Practice, 22(1), 1-5.

Casidy, R. (2013). How great thy brand: The impact of church branding on perceived benefits. International Journal of Nonprofit and Voluntary Sector Marketing, 18(3), 231-239.

Chad, P., Kyriazis, E., \& Motion, J. (2013). Development of a market orientation research agenda for the nonprofit sector. Journal of Nonprofit \& Public Sector Marketing, 25(1), 1-27. 
Chang, Y., Wang, X., \& Arnett, D. B. (2018). Enhancing firm performance: The role of brand orientation in business-to-business marketing. Industrial Marketing Management, 72, 17-25.

Cooke, D. (2010). Building social capital through corporate social investment. Asia-Pacific Journal of Business Administration, 2(1), 71-87.

Curran, R., Taheri, B., MacIntosh, R., \& O'Gorman, K. (2016). Nonprofit brand heritage: Its ability to influence volunteer retention, engagement, and satisfaction. Nonprofit and Voluntary Sector Quarterly, 45(6), 1234-1257.

Doar Institute. (2018). Best NGOs Guide 2018. Retrieved on December 15, 2020 from https://www.insti tutodoar.org/wp-content/uploads/2019/01/Guia_100_melhores_ONGs_completo.pdf.

Durgee, J. F. (2016). Exploring what nonprofit branding can learn from contemporary art. International Journal of Nonprofit and Voluntary Sector Marketing, 21(2), 73-81.

Ernst, H., Kahle, H. N., Dubiel, A., Prabhu, J., \& Subramaniam, M. (2015). The antecedents and consequences of affordable value innovations for emerging markets. Journal of Product Innovation Management, 32(1), 65-79.

Evans, J., Bridson, K., \& Rentschler, R. (2012). Drivers, impediments and manifestations of brand orientation: An international museum study. European Journal of Marketing, 46(11-12), 1457-1475.

Ewing, M. T., \& Napoli, J. (2005). Developing and validating a multidimensional nonprofit brand orientation scale. Journal of Business Research, 58(6), 841-853.

Garg, E., Swami, S., \& Malhotra, S. K. (2019). Branding effectiveness measurement in non-profit environment. Journal of Advances in Management Research, 16(1), 4-22.

Hair Jr., J. F., Black, W. C., Babin, B. J., Anderson, R. E., \& Tatham, R. L. (2009). Multivariate Data Analysis (7th ed.). Prentice Hall.

Hankinson, P. (2000). Brand orientation in charity organisations: Qualitative research into key charity sectors. International Journal of Nonprofit and Voluntary Sector Marketing, 5(3), 207-219.

Hankinson, P. (2001). Brand orientation in the charity sector: A framework for discussion and research. International Journal of Nonprofit and Voluntary Sector Marketing, 6(3), 231-242.

Hankinson, P. (2002). The impact of brand orientation on managerial practice: A quantitative study of the UK's top 500 fundraising managers. International Journal of Nonprofit and Voluntary Sector Marketing, 7(1), 30-44.

Hopstein, G., \& Peres, M. (2021). Covid emergency studies the role and protagonism of civil society in the facing of the covid-19 pandemic in Brazil. GIFE - Grupo de Institutos Fundações e Empresas. Retrieved on March 22, 2021. Available at: https://mapaosc.ipea.gov.br/post/113/covid-emergency-studies-therole-and-protagonism-ofcivil-society-in-the-facing-of-the-covid19-pandemic-in-brazil.

Institute for the Development of Social Investment. (2020). Brazil Giving Report 2020. Retrieved on 01 November, 2020, from https://www.idis.org.br/wp-content/uploads/2020/07/CAF_BrazilGivi ng2020.pdf.

Institute of Applied Economic Research [IPEA] (2021). Mapa das Organizações da Sociedade Civil. Retrieved on 16 October, 2021, from https://mapaosc.ipea.gov.br/.

Khan, H., \& Ede, D. (2009). How do not-for-profit SMEs attempt to develop a strong brand in an increasingly saturated market? Journal of Small Business and Enterprise Development, 16(2), 335-354.

King, C., \& Grace, D. (2010). Building and measuring employee-based brand equity. European Journal of Marketing, 44(7/8), 938-971.

King, C., \& So, K. K. F. (2015). Enhancing hotel employees' brand understanding and brand-building behavior in China. Journal of Hospitality and Tourism Research, 39(4), 492-516.

King, C., So, K. K. F., \& Grace, D. (2013). The influence of service brand orientation on hotel employees' attitude and behaviors in China. International Journal of Hospitality Management, 34, 172-180.

Kuti, E. (1999). Different eastern European countries at different crossroads. Voluntas: International Journal of Voluntary and Nonprofit Organizations, 10(1), 51-60.

Laidler Kylander, N., \& Simonin, B. (2009). How international nonprofits build brand equity. International Journal of Nonprofit and Voluntary Sector Marketing, 14(1), 57-69.

Laukkanen, T., Nagy, G., Hirvonen, S., Reijonen, H., \& Pasanen, M. (2013). The effect of strategic orientations on business performance in SMEs: A multigroup analysis comparing Hungary and Finland. International Marketing Review, 30(6), 510-535.

Lee, D., \& Markham, P. A. (2015). Fundraising-related market orientation among non-profit organisations in Hong Kong: A literature review and research agenda [Working Paper $\mathrm{N}^{\circ}$ 7203]. The Hong Kong Polytechnic University, College of Professional and Continuing Education, School of Professional Education and Executive Development, Hong Kong. 
Liu, G., Chapleo, C., Ko, W. W., \& Ngugi, I. K. (2015). The role of internal branding in nonprofit brand management: An empirical investigation. Nonprofit and Voluntary Sector Quarterly, 44(2), 319-339.

Liu, G., Ko, W. W., \& Chapleo, C. (2017). Managing employee attention and internal branding. Journal of Business Research, 79, 1-11.

Lopez, F. (2018). Perfil das organizações da sociedade civil no Brasil. IPEA.

Mainardes, E. W., Laurett, R., Degasperi, N. C. P., \& Lasso, S. V. (2017). External motivators for donation of money and/or goods. International Journal of Nonprofit and Voluntary Sector Marketing, 22(2), 1-11.

Maleki, F., \& Hosseini, S. M. (2020). Charity donation intention via m-payment apps: Donor-related, m-payment system-related, or charity brand-related factors, which one is overkill? International Review on Public and Nonprofit Marketing, 17(4), 409-443.

Michel, G., \& Rieunier, S. (2012). Nonprofit brand image and typicality influences on charitable giving. Journal of Business Research, 65(5), 701-707.

Moraes, S. G., \& Strehlau, V. I. (2020). Country or brand: What matters to younger millennials? Brazilian Business Review, 17(3), 275-292.

Mulyanegara, R. C. (2011). The role of brand orientation in church participation: An empirical examination. Journal of Nonprofit \& Public Sector Marketing, 23(3), 226-247.

Napoli, J. (2006). The impact of nonprofit brand orientation on organisational performance. Journal of Marketing Management, 22(7-8), 673-694.

Paul, J. (2020). Marketing in emerging markets: A review, theoretical synthesis and extension. International Journal of Emerging Markets, 15(3), 446-468.

Randle, M., Leisch, F., \& Dolnicar, S. (2013). Competition or collaboration? The effect of non-profit brand image on volunteer recruitment strategy. Journal of Brand Management, 20(8), 689-704.

Richelieu, A., \& Korai, B. (2012). The international expansion of religious organizations in Africa. International Journal of Nonprofit and Voluntary Sector Marketing, 17(2), 144-155.

Sepulcri, L., Mainardes, E., \& Marchiori, D. (2020). Brand orientation: A systematic literature review and research agenda. Spanish Journal of Marketing - ESIC, 24(1), 97-113.

Sepulcri, L., Mainardes, E., \& Pascuci, L. (2020, July). Nonprofit brand orientation in an emerging country: Antecedents, outcomes and barriers. Paper presented at the meeting of XIX International Congress on Public and Nonprofit Marketing.

Shankar, V., \& Narang, U. (2019). Emerging market innovations: Unique and differential drivers, practitioner implications, and research agenda. Journal of the Academy of Marketing Science, 48, 1030-1052.

Sheth, J. N. (2011). Impact of emerging markets on marketing: Rethinking existing perspectives and practices. Journal of Marketing, 75(4), 166-182.

da Silva, L. C., Mainardes, E. W., Teixeira, A. M. C., \& Costa Júnior, L. (2020a). Brand orientation of nonprofit organizations and its relationship with the attitude toward charity and donation intention. International Review on Public and Nonprofit Marketing, 17, 353-373.

da Silva, L. C., Mainardes, E. W., Teixeira, A. M. C., \& Costa Júnior, L. (2020b). Cause-related marketing in online environment: The role of brand-cause fit, perceived value, and trust. International Review on Public and Nonprofit Marketing, 17(2), 135-157.

Stride, H., \& Lee, S. (2007). No logo? No way. Branding in the non-profit sector. Journal of Marketing Management, 23(1-2), 107-122.

Tilley, C. (1999). Built-in branding: How to engineer a leadership brand. Journal of Marketing Management, 15(1-3), 181-191.

Toepler, S., Pape, U., \& Benevolenski, V. (2020). Subnational variations in government-nonprofit relations: A comparative analysis of regional differences within Russia. Journal of Comparative Policy Analysis: Research and Practice, 22(1), 47-65.

Urde, M. (1994). Brand orientation: A strategy for survival. Journal of Consumer Marketing, 11(3), 18-32.

Urde, M. (1999). Brand orientation: A mindset for building brands into strategic resources. Journal of Marketing Management, 15(1-3), 117-133.

Urde, M., Baumgarth, C., \& Merrilees, B. (2013). Brand orientation and market orientation: From alternatives to synergy. Journal of Business Research, 66(1), 13-20.

Venable, B. T., Rose, G. M., Bush, V. D., \& Gilbert, F. W. (2005). The role of brand personality in charitable giving: An assessment and validation. Journal of the Academy of Marketing Science, 33(3), 295-312. 
Voeth, M., \& Herbst, U. (2008). The concept of brand personality as an instrument for advanced nonprofit branding-an empirical analysis. Journal of Nonprofit \& Public Sector Marketing, 19(1), 71-97.

Wirtz, J., den Ambtman, A., Bloemer, J., Horváth, C., Ramaseshan, B., van de Klundert, J., Canli, Z. G., \& Kandampully, J. (2013). Managing brands and customer engagement in online brand communities. Journal of Service Management, 24(3), 223-244.

Wong, H. Y., \& Merrilees, B. (2005). A brand orientation typology for SMEs: A case research approach. The Journal of Product and Brand Management, 14(3), 155-162.

Wong, H. Y., \& Merrilees, B. (2015). An empirical study of the antecedents and consequences of brand engagement. Marketing Intelligence and Planning, 33(4), 575-591.

Zhang, J., Jiang, Y., Shabbir, R., \& Zhu, M. (2016). How brand orientation impacts B2B service brand equity? An empirical study among Chinese firms. Journal of Business \& Industrial Marketing, 31(1), 83-98.

Publisher's note Springer Nature remains neutral with regard to jurisdictional claims in published maps and institutional affiliations. 